\title{
"Política de Empleo" y Sistema de Relaciones Laborales: La Autonomía Colectiva como fuente del Derecho del Empleo
}

\author{
José Luis Monereo Pérez \\ Universidad de Granada \\ Cristóbal Molina Navarrete \\ Universidad de Jaén
}

RESUMEN:

El empleo es uno de los principales objetivos de las políticas preblicas europeas. además de una -Cuestión social. que afecta al conjunto de la sociedad, y más especificamente a los agentes sociales. En esta linea, el diálogo social, en gran medida, jugará un papel importante en la Estrategia Europea para el Empleo. Ambos, empresas y trabajadores, han aceptado esta responsabilidad, como se demuestra en los Pactos Territoriales de Empleo y en las cläusulas específicas de empleo en la negociación colectiva. Este estudio ofrece un análisis crítico del tradicional régimen juridico del empleo.

Palabras clave: cuestión social, diálogo social. Estrategia Europea para el Empleo, Paclos Territoriales de Empleo, negociación colectiva.

ABSTRACT:

Employment is one of the main objectives of public policies in Europe. At the same time unemployment reveals a "social question" that affects the whole society, and more specifically to social agents. In this way, "Social Dialogue", in a very extensive way, will play an important part in the European Strategy for Employment. Both, enterprises and workers have accepted this responsibility as shown in the Local Employment Agreements (Pactos Territoriales de Empleo) and specific clauses of employment in. Collective Bargaining. This article presents a critical analysis of the conventional judicial regimen of employment.

Key words: social question, social dialogue, European Strategy for Employment, Local Employment Agreements, Collective Bargaining. 


\section{INTRODUCCIÓN}

Cualquiera que sea la opción que se adopte respecto del encuadramiento de esta nueva rama del ordenamiento jurídico, la que para nosotros es el •Derecho del Empleo", parece ahora ya claro que esta materia no queda reservada a la intervención de los poderes públicos, si bien a éstos siguen correspondiendo las principales competencias, en particular, junto a la normativa heterónoma, la financiación o aportación de los fondos necesarios para impulsar las diferentes medidas. La "crisis de empleo* que han venido experimentado las sociedades industrializadas en el último cuarto del siglo pasado se ha revelado como una auténtica y genuina "cuestión social", de tal envergadura que reclama la preocupación y el compromiso de la sociedad entera, y muy particularmente de los interlocutores sociales ${ }^{1}$.

Desde esta responsabilización social del problema del desempleo se explica, y se justifica, que la regulación de la materia relativa al empleo en general, y a las políticas de empleo en particular, adquiera una creciente - aunque todavía no satisfactoriarelevancia en el ámbito de la autonomía colectiva. La convicción cada vez más extendida de que el empleo es una acuestión social. en sentido estructural lleva a plantear la necesidad de buscar medidas de solución, en orden a una más eficaz, equitativa y racional distribución del empleo, no sólo por el poder público, sino también por los agentes sociales. La negociación colectiva es actualmente, en cuanto mecanismo primordial de regulación institucional del mercado de trabajo y de distribución de riqueza, un instrumento fundamental para la política de empleo. Las últimas experiencias tanto de concertación social cuanto de negociación colectiva así lo acreditan, configurándose los objetivos de amantenimiento de los actuales niveles de empleo, promoción dè una mayor estabilidad y calidad a este empleo existente e, incluso, la creación de, nuevos empleos, como ejes cardinales de la más reciente política de intercambio colectivo-sindical ${ }^{2}$.

1. Como gráfica - también algo demagógicamente- se observara hace unos años por uno de los principales responsables de la política de empleo española, el objeto de crear empleo es de tal trascendencia, -que no cabe en las hojas del BOE, pues requiere el entusiamos de todo un pueblo. vid. PEÑA PINTO, M. La Reforma Laboral: Derecho y Empleo. La Ley. n.4048, 31.5.1996.

2. La negociación colectiva concurrirá, pues, con la ley no ya sólo en la construcción del sistema regulador del trabajo asalariado, según la tradicional imagen de la negociación concesiva, sino también en la dificil tarea de flexibilizar y reducir las tutelas y redistribución sea de recursos, tanto privados como públicos, sea de "sacrificios- entre trabajadores a fin de favorecer, mediante esta nueva política de intercambios colectivos, el incremento, o cuando menos el mantenimiento, de la ocupación. En las sociedades actuales el -verdadero peligro para la persona no está ya tanto en la relación de trabajo, ahora adecuadamente disciplinao, cuanto en la falta de trabajo. En este sentido, véase CES. Memoria sobre la situación socioeconómica y laboral de España en 1998, Madrid, CES, 1999, págs.264 y sigs. En la negociación colectiva, por ejemplo, Seguros y reaseguros (Empresas de). Res.17-XI-1998. BOE. 11.XII.1998. I.L.4888, que dedica el Cap.XIII a la .Política de empleo- 
Los trabajadores no son ya considerados por la negociación colectiva sólo como parte de una relacion (=inclusión real en el mercado de trabajo=), sino tambien como sujetos del mercado a la busca de una relación, ya sea en un momento previo a la celebración del contrato ( =inclusión potencial $=$ ) ya incluso en un momento posterior al mismo (=sujeto de una relación postcontractual=). Junto a la tutela de las condiciones de trabajo, según una función clásica atribuida a la negociación colectiva, la defensa y, en lo posible, el incremento neto, de los niveles de empleo se configura cada vez más como una nueva función asumida por la autonomía colectiva. Con origen en la técnica de prejubilación y en las medidas de recolocación, a su vez inicialmente vinculadas a los procesos extraordinarios de "reconversión industrial" de principios de la década de los años 80 , las cláusulas de empleo representan uno de los grupos de materias donde ha habido más apertura para la regulación convencional, por lo que la política de empleo reviste una importante base concertada (=técnica de la concertación social=) y convencional o negociada (=técnica de la negociación colectiva $=)^{3}$.

Los agentes sociales han conseguido -con la complicidad del poder público, que el convenio colectivo, entendido en sentido amplio, deje de estar constreñido a rígidos contenidos negociales. A partir de ahora, junto a contenidos típicos, como el salario, el tiempo de trabajo, clasificación profesional, se añaden nuevos contenidos para albergar dentro de la negociación cláusulados normativos y obligacionales de distintas características. La lucha contra el desempleo y a favor del derecho a la inserción profesional se convierte en objeto de intercambio no sólo “socio-políticon (concertación) sino también colectivo-profesional. Está empezando a gestarse la gran transformación que eclosionará en este nuevo siglo, aunque los resultados en el umbral del mismo no sean satisfactorios.

En efecto, aunque todavía su influencia en la negociación colectiva no había venido siendo demasiado amplia, como se deduce de los diversos Informes estatales y autonómicos al respecto, no cabe duda de la tendencia -y ello se refleja también en

3. Tales contenidos reflejan ya en sí que se está muy lejos de los contenidos típicos legados por la tradicional cultura negocial.Vid.ampliamente, MONEREO PEREZJ.L.: "El tratamiento de la relación postcontractual en el marco de una negociación colectiva renovada", en COMISION CONSULTIVA NACIONAL DE CONVENIOS COLECTTVOS.:La negociación colectiva en el escenario del año 2000. XII Jornadas de Estudio de la Negociación Colectiva, Madrid, MTAS, 1999, págs.91 a 246; Id.: "Teoría jurídica del convenio colectivo: su elaboración en la ciencia del Derecho, Estudio Preliminar a la obra de GALLART FOLCH,A.: Las convenciones colectivas de condiciones de trabajo, Granada, Ed.Comares, 2000, passim. También R.DE LUCA TAMAJO.-Evoluzione dei contenuti y delle tipologie della contrattazione collettiva.. RIDL. 1985-1. p.16 y sgs. Para una perspectiva europea más amplia vid. Aa.Vv. (coord: A.Supiot). Trabajo y Empleo. Tirant Lo Blanch. Valencia.200. págs.157-158. 
las más recientes Memorias del CES y del CARL ${ }^{4}$ a una progresiva implantación. En general, estas cláusulas sobre èmpleo muestran la preocupación de la negociación colectiva por los problemas relacionados con la conservación y la creación de nuevos empleos, y fruto de ello es la inclusión en los convenios y acuerdos colectivos de estipulaciones convencionales encaminadas a realizar una política negocial de empleo dentro del ámbito de aplicación considerado, hasta el punto de ser cada vez más frecuente dedicarle un Capítulo específico. Aunque sin estar todavía ni mucho menos generalizados, en estos cuerpos normativos encontramos statu nascenti un régimen de gestión y tutela de la dimensión ocupacional de la empresa o sector concernido por el convenio, concretado tanto en cláusulas de mantenimiento de las tasas de empleo ya existente, de mejora de la calidad del mismo y, en menor medida, de creación o fomento de nuevos empleos 5 .

No obstante, su lógica preferente sigue siendo defensiva, en primer lugar, en el sentido de que la mayoría de las cláusulas tratan de garantizar el mantenimiento del. volumen de empleo y de puestos de trabajo existentes, más que la verdadera creación neta de empleo ${ }^{6}$. En segundo lugar, porque en muchos casos se trata de medidas de racionalización y distribución del empleo actualmente existente (reparto del tiempo de trabajo; jubilación anticipada, contrato de relevo, fomento de la conversión del trabajo temporal en empleo estable, etcétera). Por lo demás, finalmente, desde el punto de vista de la eficacia real de las medidas laborales en cuestión, cabe señalar que en muchos casos muchas de estas estipulaciones convencionales no van más allá de simples declaraciones programáticas respecto la conveniencia de mantener el nivel de empleo existente y promover la creación de nuevos puestos de trabajo.

En este trabajo pretendemos suministrar un cuadro general, lo más detenido y completo posible, de las diferentes vías de recepción consensuada de la política de empleo, proporcionando un mapa de las principales cláusulas de empleo recogidas en la negociación colectiva de nuestro país. Al mismo tiempo, pretendemos realizar un balance

4. Véase la Memoria del CES, CES: Economía, trabajo y sociedad. España 1998. Memoria sobre la situación socieconómica y laboral. Madrid. CES. 1999. Ese fenómeno expansivo se refleja igualmente en la MEMORIA C.A.R.L.: La negociación colectiva en Andalucía. Año 1998, Sevilla, Junta de Andalucía, Consejo Andaluz de Relaciones Laborales, 1999, espec., cap.VI, págs.247 y sigs -también en la de 1999-. De ambos estudios se desprenden que los mecanismos dirigidos al mantenimiento del empleo en su conjunto son los que más incorporan las cláusulas de empleo, seguidos muy de cerca por las medidas previstas respecto a la jubilación anticipada.

5. vid. MOLINA NAVARRETE, C-MOLINA HERMOSIA, O-VILLAR CAÑADA, I: ¿Derecbo y Empleo: Balance de las Aplicaciones prácticas de la reforma laboral de 1997. Temas Laborales. n.54.2000.pags.61 y sgs.

6. Vid. OJEDA AVILES,A.El contenido de la negociación colectiva en materia de empleo y ocupación. En AA.VV. Empleo, contratación y negociación colectiva. X Jornadas de Estudio sobre Negociación Colectiva. Madrid. MTAS. 1999. págs.134 y sigs. 
crítico de las principales aportaciones realizadas por los denominados “Pactos Autonómicos de Empleo", muchos de los cuales han sido renovados en estos últimos meses o están en fase de renovación, una de las principales expresiones no sólo la de la nueva dimensión territorial que asume la política, comunitaria y nacional, de empleo sino también del nuevo sentido y alcance del clásico proceso de concertación social.

II. La política de empleo como ambito privileglado para la CONCERTACión SOCIAL: La NUEVA DIMENSIÓN TERRITORIAL.

Históricamente las cláusulas sobre empleo han estado vinculadas en nuestro país a la dinámica de la denominada "Concertación social". Ha sido así desde los grandes pactos sociales (ANE, AES y los acuerdos marco bilaterales pero encadenados a la políticas públicas ${ }^{7}$ ), pasando por los recientes acuerdos marco interconfederales de 1997 (bilaterales, pero con la presencia implícita del Gobierno, sobre todo, y significativamente, respecto al acuerdo sobre Estabilidad en el Empleo), y llegar a los numeros acuerdos realizados en las distintas Comunidades Autónomas. Las políticas de concertación social permiten articular la negociación colectiva bilateral con la negociación política trilateral, influyendo -y condicionando- en la orientación de las políticas públicas. También en materia de empleo el fenómeno de la concertación social se ha vinculado estrechamente a un doble proceso de regulación jurídica: la determinación de los objetivos y la orientación de los acuerdos y convenios colectivos, sea interprofesionales ex art.83 LET sean profesionales, por un lado, la fijación de los contenidos y líneas inspiradoras de la legislación pública, a través de la denominada «legislación negociada", por otro.

Las denominadas "políticas activas de empleom en su conjunto ${ }^{8}$ siguen estando encadenadas a los procesos de concertación social. Aunque ahora asumen principalmente un carácter más local o territorial (es de sobra conocido el auge de la concertación social en el gobierno de nuestras Comunidades Autónomas) y se sitúan preferente sobre un ámbito de objetivos y materias concretas, a diferencia en los procesos de macroconcertación social a escala nacional y con pretensiones globalizadoras ${ }^{9}$, no cabe olvidar su dimensión también

7. Para una aproximación clásica vid. VILLA,L.E.: Los grandes pactos colectivos a partir de la transición democrática. Madrid, MTSS, 1985. Para el estudio monográfico más completo sobre los pactos sociales y su incidencia en el ámbito laboral vid. MORENO VIDA.M.N.:Los pactos sociales en el Derecho del Trabajo, Granada (Universidad). 1989.. Para una aproximación a la última fase de estos procesos vid. MONEREO PÉREZJ.L.: Concertación y diálogo social. Valladolid. Lex Nova, 1999.

8. En sentido estricto forman parte de estas políticas activas de empleo la política de colocación y orientación laborales; la política de fomento del empleo (y del autoempleo); la política de formación profesional y la política de flexibilidad, asi como la política de reordenación del tiempo de trabajo.

9. Sobre las causas de esta transformación del modelo de concertación social, puede consultarse recientemente MONEREO PEREZJ.L.: Concertación y diálogo social, Valladolid, Lex Nova, 1999. 
empresarial. Así, en gran medida las leyes negociadas han intentado mantener y fomentar el empleo mediante un incremento de la libertad empresarial de gestión de la mano de obra. En el plano de la empresa se ha intentado obtener la máxima capacidad de empleo de la organización pública mediante una utilización racionalizada del mayor número de mano de obra afecta a los procesos productivos. En este sentido, a través de políticas de gestión consensuada del gobierno de la empresa se ha potenciado al máximo sus capacidades de empleo, o al menos se ha procurado contener la tendencia expulsiva de mano de obra propia de la actual "economía del tiempo de trabajo", sin mermar su rentabilidad ${ }^{10}$.

La concertación social es tanto un procedimiento de gobernalidad jurídico-política como un mecanismo de dar respuesta a la complejidad creciente de las relaciones sociales. El cuadro de medidas que suelen contener es muy variado: fomento o apoyo de la contratación, fomento o apoyo al autoempleo, economía social y a la empresa, apoyo a la formación específica destinada al empleo y acciones de orientación e intermediación en el mercado de trabajo, aunque pueden entrar en otras materias (como salud laboral, materias conexas como política industrial y de desarrollo empresarial.... ${ }^{11}$, dejando de ser así pactos monográficos sobre materias concretas, en el sentido del art.83 ET. Muchos de los acuerdos sociales sobre el empleo se inclinan hacia el modelo de competitividad ofensiva (que apuesta por la innovación, la calidad del trabajo, la participación de los trabajadores en la producción y en la dirección de la empresa y la formación) y rehusan establecer medidas propias de la competitividad defensiva (que impulsar políticas de reducción de los costes de mano de obra, precarización del trabajo e implantan sistemas de organización del trabajo basados en la disciplina y en la separación rígida entre las actividades de concepción y de ejecución) ${ }^{12}$.

10. Una oportunidad la ofrece la gestión ordinaria y la gestión extraordinaria mediante la elaboración de planes sociales negociados en las empresas en crisis o en reestructuración productiva, en una coyuntura donde la reestructuración aparece como un mecanismo permanente de gestión de la empresa, tendiéndose a difuminar la antes predominante visión excepcional o extraordinaria.

11. Un estudio empírico de la estructura y contenido de estos pactos de empleo puede encontrarse en ARAGÓN,J.,ROCHA,F.,y TORRENTS J.: Pactos y medidas de fomento del empleo en las Comunidades Autónomas, Madrid, MTAS, 2000 , págs. 97 y sigs.

12. Véase CROUCH,C.: "Ottimisti e pessimisti nel dibattito sul mercato del lavoro. Un commento", en Stato e Mercato, núm.56 (1999), passim.; DEAKIN-WILKINSON: «Il diritto del lavoro e la teoria economica: una rivisitazione”, en G.D.T.R.I., núm.84 (1999), págs.587 y sigs. La medidas de competitividad .ofensiva* (impulsadas desde las políticas democrático-sociales), tratan de incidir sobre la oferta de trabajo con la finalidad de adaptarla a las previsiones de crecimiento de la demanda de empleo en el cuadro de un modelo económico-productivo de carácter postfordista. Por su parte, las medidas de competitividad đdefensiva" (impulsadas sobre todo por las políticas liberales), buscan la reducción de los costes sociales, favorecen la implantación de medidas de flexibilidad "nocivan reducciendo la oferta de empleo. Bajo este -eslogán. de liberar al mercado de los impedimentos externos derivados del marco jurídico e institucional, intentan implantar un modelo de flexibilidad de mercado, regido principalmente por las reglas contractuales, que remiten a la respectiva fuerza negocial de las partes contratantes. 
Los -Pactos de empleón de la Comunidades Autónomas y las medidas de apoyo a la creación de empleo se insertan en el cuadro del Plan de Acción para el Empleo del Reino de España, que se ha venido aprobando anualmente desde 1998 en el marco de las políticas de coordinación en materia de empleo dentro de la Unión Europea ("Directrices para el Empleon). Como es sabido, el Consejo Europeo sobre el Empleo celebrado en Luxemburgo (1997) implicó la aplicación práctica del nuevo Título de Empleo del Tratado de Amsterdam, centrando la actuación de los Estados en 4 grandes ejes o Pilares que luego fueron recogidos por los Planes Nacionales - vg. Pilar I: mejora de la capacidad de inserción profesional; Pilar II: Desarrollo del espíritu de empresa; Pilar III: Fomento de capacidad de la adaptación de los trabajadores y las empresas; Pilar IV: reforzar las políticas de igualdad de oportunidades en el mercado de trabajo- La evaluación de los primeros Planes de Acción para el Empleo de los Estados miembros tuvo lugar en el Consejo Europeo de Cardiff (1998), consolidándose esta estrategia comunitaria en el Consejo Europeo de Colonia (1999), que sentó las bases de una política comunitaria de empleo centrada en el diálogo macroeconómico entre los interlocutores institucionales y los sociales, al objeto de crear las condiciones más adecuadas para un entorno económico favorable, sin el cual no habría perspectiva real y duradera de crecimiento del empleo".

Por lo que refiere a esta política comunitaria de empleo parece estar en una situación de transición hacia políticas de carácter más ofensivo, potenciando políticas activas e incorporando en dichas políticas una lógica de "empleabilidad" ", la cual incide sobre los factores causales del desempleo y la relevancia de las estrategias formativas y de capacitación. Esta noción se inscribe en la más amplia orientación comunitaria de primar las políticas activas de empleo sobre las política pasivas de corte prestacional clásico. Adviértase que la noción de empleabilidad", que constituye el denominado Pilar I de la estrategia europea por el empleo, se vincula estrecha-

13. vid. el denominado .Pacto Europeo para el Empleo. conocido como proceso de Colonia, que integra todas las medidas europeas adoptadas en el ámbito del empleo, mediante la combinación de políticas macroeconómicas (proceso de Colonia), la estrategia coordinada del empleo (Luxemburgo) y las reformas económicas (Cardiff). Esta estrategia fue reafirmada en el Consejo Europeo de Helsinki (1999). El favor comunitario por los denominados .Pactos Territoriales para el Empleo- aparece en numerosos documentos e iniciativas europeas. Así, pej., Comisión Europea: .Pactos territoriales por el empleo: ejemplo de buenas prácticas. Empleo y Asuntos Sociales. 1997; Dictamen sobre los Pactos territoriales para el empleo. Dictamenes e Informe del CES, n.1129. Luxemburgo. 1998

14. Para el origen de esta noción, véase GALBRAITHJ.K.: El nuevo Estado industrial, trad. de M.Sacristán, Barcelona, Ariel, 1974, págs.293 y sigs., que precisamente ya hacia referencia a los trabajadores -inempleables por falta de educación. (Ibid.,pág.305). Sobre el tema véase CHASSARD Y BOSCO: . $L$ 'émergence du concept d'employabilité. Droit Social, núm. 11 (1998), págs.903 y sigs.: SERRANO PASCUAL, A.: «El concepto de empleabilidad en la estrategia europea de lucba contra el desempleo: una perspectiva critica. RMTAS, núm. 21 (2000), págs.137 y sigs. 
mente con la orientación comunitaria hacia la "constitución de un Estado activo de bienestar ${ }^{15}$. En esta línea, se ha destacado cómo los sistemas de educación y formación europeos necesitan adaptarse tanto a las demandas de la sociedad del conocimiento como a la necesidad de mejorar el nivel y calidad del empleo. Éstos tendrán que ofrecer oportunidades de aprendizaje y formación adaptadas a grupos destinatarios en diversas etapas de sus vidas: jóvenes, adultos parados y ocupados que corren el riesgo de ver sus cualificaciones desbordadas por un proceso de cambio rápido... ${ }^{16}$.

Precisamente, a organizar, regular e implementar una política sistemática y coherente de acción en favor de estos objetivos se orientan, con eficacia y metodología desigual, los denominados Planes Nacionales de Empleo, que de componen de un conjunto de medidas integradas. En relación a ellas se instrumentan una serie de acciones públicas (que no $s$ iempre se concretan jurídicamente), consistentes en facilitar la conciliación de la vida familiar y la vida laboral de los trabajadores, promesa de aprobación de una Ley de Inserción Socioloboral, incumplida desde 1998, al igual que el compromiso de reformar la Ley Básica de Empleo, ahora ya obsoleta, restricción de los trámites administrativos para la creación de pymes (ampliación del sistema de "ventanilla única"), intensificación de las medidas de política activa (Talleres para el Empleo, "Compromiso voluntario de actividad", etcétera), y, en fin, fomento de líneas de desarrollo local (incidiendo en el programa de Iniciativas Locales de Empleo y realización del Plan de Choque en diversos municipios en los que existe un elevado nivel de desempleo).

En conexión con el impulso de las orientaciones comunitarias de territorialización de las políticas de empleo (tanto en su concepción como en su instrumentación y aplicación), las Comunidades Autónomas están realizando notorios esfuerzos para articular una política de empleo concertada con los agentes

15. En tal sentido se indica que alas personas constituyen en Europa el principal activo, por lo que deberian convertirse en el centro de las políticas de la Unión. La inversión en capital humano y el fomento de un Estado de bienestar activo y dinámico serán esenciales tanto para que Europa ocupe un lugar en la economía basada en el conocimiento como para garantizar que el surgimiento de esta nueva eonomía no incremente los problemas sociales existentes de desempleo, exclusión social y pobrezan.Conclusión 24 de las Conclusiones de la Presidencia del Consejo Europeo de Lisboa (23 y 24 de marzo de 2000). Recogidas en CES: La estrategia europea de empleo. Colección Informes. 1/2001. En detalle sobre este concepto vid. MONEREO, J.L.-MOLINA, C.El derecho a la renta de inserciōn. Granada. Comares.1999.

16. En el Consejo Europeo Extraordinario celebrado en Lisboa ( marzo 2000), que introduce el nuevo método político denominado "método abierto de coordinación",, una de las cuestiones especialmente analizadas para la revisión de la estrategia europea de empleo fue la de reforzar el papel de los interlocutores sociales llamados a asumir con mayor intensidad en el futuro su papel en la aplicación y supervisión de las directrices que dependen de ellos. vid. Decisión del Consejo de 19.1.1991,2001/63/CE 
sociales, integrando el conjunto de medidas necesarias para crear o mantener los niveles de empleo (medidas económicas y jurídicas pertenecientes a distintas ramas del sistema jurídico). Estas políticas concertadas en el espacio autonómico han tenido la virtualidad de adaptar los "Planes" de empleo a las exigencias y circunstancias específicas de la Comunidad Autónoma. Estos pactos o acuerdos de empleo tratan de consensuar entre los agentes económicos y sociales las medidas de intervención pública y de establecer reglas sobre la organización y el fomento del empleo en sentido muy amplio, abarcando desde la tradicionales medidas en materia de contratación, sea de carácter general sea en favor de colectivos determinados (políticas selectivas), hasta el autoempleo, ya de carácter individual ya, sobre todo, colectivo ( $\mathrm{vg}$. economía social), especialmente en el marco de los "nuevos yacimientos de empleo" (NYE), pasando por una variada gama de medidas de apoyo a la formación en alternancia (política de formación ocupacional) y otros servicios de orientación e intermediación en el mercado de trabajo (política de colocación) ${ }^{17}$.

Puesto que no en todas las Comunidades Autónomas concurren las mismas circunstancias socio-económicas y políticas, es posible diferenciar los distintos Pactos o Acuerdos de Empleo en atención a la complejidad de su estructura, de modo que mientras que unos se limitan a contemplar medidas exclusiva o preferentemente orientadas hacia actuaciones en materia de empleo (ej. Cataluña, Madrid, Pais Vasco, Castilla y León; Canarias, Navarra-, otros, en cambio, se enmarcan en un "Plan" mucho más amplio, acorde con la propia complejidad de la política de empleo, en cuanto que ésta se ve afectada por una amplísima gama de factores que influyen sobre el equilibrio de la oferta y la demanda de empleo-ej. Andalucía, Asturias, Aragón, Baleares, Cantabria, Castilla-La Mancha, Extremadura, Galicia, Murcia, La Rioja, Valencia-. Las complejas. interrelaciones existentes entre todos los mercados de factores y productos, así como con los sistemas de educación y formación, aparecen ampliamente recogidas en estos Pactos de estructura especialmente compleja, lo que por otro lado se revela coherente con la estrategia europea por el empleo, que ha opta-

17. Aunque todos ellos evidencial un significativo grado de concertación, al estar participado por los principales interlocutores sociales, unos tienen carácter tripartito, la gran mayoria, según el paradigma clásico de la concertación, mientras que otros, los menos, tienen carácter bipartito, bien entre Administración y sindicatos -j. Asturias, Madrid- bien entre sindicatos y empresarios - ej. País Vasco-. Incluso alguno ha sido desarrollado por acción gubernamental sólo, aún contando con el apoyo de algún sindicato más representativo. Es el caso del Plan de Empleo de Castilla y León. vid. ALVAREZ, C. -Nuevos retos para la política activas de empleo. Economistas, n.77, 1998; id. .Diálogo social y reforma laboral: nuevos avances. Economistas, n.80.1999; CALVO, R.-PEREZ, D.*Análisis del AIEE y el Acuerdo por el Empleo en Extremadura. CCOO: El Acuerdo Interconfederal para la Estabilidad en el Empleo y los Pactos Territoriales por el Empleo. Documento de Trabajo. CCOO.Madrid.1999. 
do por un método de coordinación de la política de empleo con el resto de políticas, sectoriales y horizontales, integrando aspectos tales como la formación, la innovación, el desarrollo tecnológico, la cooperación intermperesarial a nivel regional, el ambiente, el turismo... ${ }^{18}$.

Por otro lado, en lo que concierne a sus contenidos, esto es, a sus líneas de actuación, es posible encontrar un elevádisimo grado de uniformidad entre los diferentes Acuerdos en torno a los ejes centrales de la política de empleo - fomento del empleo estable; promoción del autoempleo y economía social, ambos en el marco de los nuevos yacimientos de empleo y de las iniciativas locales de empleo; reforzamiento de la formación profesional en sus diferentes subsistemas; profundización en el servicio público de colocación y mejora del principio de igualdad de oportunidades, a través de medidas de preferencia y reinserción de colectivos más desfavorecidos-, consecuencia tanto del efecto de la estrategia europea por el empleo como de los Planes Nacionales y AIEE. Ahora bien, esta convergencia se torna en divergencia no sólo cuando se trata de fijar las concretas medidas y actuaciones, prever los diferentes recursos financieros necesarios para su puesta en acción, sino también cuando se trata de integrar determinadas medidas, en particular las de fomento de la creación de empleo como consecuencia de fórmulas ligadas a la reordenación/reducción del tiempo de trabajo; normalización de la economía irregular; fomento del empleo en determinados sectores - ej. turístico, agrario-; promoción del empleo estable a través de regulaciones de contratos celebrados en el ámbito de las Administraciones Públicas... ${ }^{19}$.

En el marco de procesos de concertación de estructura particularmente compleja, con una gran tradición histórica, junto a Acuerdos como los de Aragón, Comunidad pionera en estos procesos, o Castilla-La Mancha o Comunidad Valenciana, esta última reveladora de fuertes incertidumbres sobre su grado de cumplimiento, destaca hoy la firma del $V$ Acuerdo de Concertación Social de Andalucía, firmado por el Gobierno Andaluz y los agentes sociales el 23 de mayo de 2001. Este Acuerdo de Concertación

18. vid. J.ARAGÓN et altri. Pactos...op.cit.pags.113 y sgs; CACHÓN, L-PALACIO, J.A. ^Política de Empleo en España desde el ingreso en la Unión Europea. En Miguélez, F-Prieto, C. Las relaciones de empleo en España. Siglo XXI. Madrid.1999

19. Ej. Acuerdo para el fomento del Empleo en Aragón, que introduce la contratación estable como criterio preferente para el acceso a las contrataciones públicas; Acuerdo por la estabilidad en el empleo de Castilla-La Mancha, que recoge el compromiso de la Administración regional de fomentar en los pliegos de condiciones de los contratos administrativos, la inclusión de cláusulas que garanticen de forma efectiva el aseguramiento de la continuidad en la relación laboral de los trabajadores afectados por cambios de contratista (garantía de subrogación empresarial); Acuerdo Marco para apoyar la estabilidad y la calidad del empleo de Madrid, que concede preferencias o prioridades a empresas que aseguren contratación estable -este Acuerdo ha sido impugnado por las organizaciones empresariales por considerarlo lesivo del principio de competencia-. 
Social, cuya estrategia global de empleo coincide plenamente con el nuevo Marco de Apoyo Comunitario (MAC), aprobado para el periodo 2000-2006, contenidos y objetivos de la Agenda 2000 y la aplicación de la Estrategia Europea de Empleo, así como de la Iniciativa e-Europe para el desarrollo de la Sociedad de la Información en la UE, se articula en 5 grandes ejes estratégicos: políticas activas de empleo; creación, mejora de la competitividad e internacionalización de las empresas andaluzas; sociedad del conocimiento, planificación económica y mejora de las relaciones laborales. De esta manera, en relación a los precedentes Acuerdos, el nuevo Pacto incorpora notorias novedades en su objeto, al tiempo que en los ejes tradicionales añade importantes elementos novedosos, en particular, para el ámbito estricto de las políticas activas de empleo la creación de un sistema de incentivos renovados en atención a un doble criterio, la vulnerabilidad del colectivo a que se dirige y la dimensión de la empresa, al tiempo que se pretende crear, no obstante el incumplimiento gubernamental del acuerdo para transferir las políticas activas, el Servicio Andaluz de Empleo ${ }^{20}$.

Aunque la concertación social no es en sí negociación colectiva bilateral entre los agentes sociales, los acuerdos tripartitos se coordinan con los convenios colectivos de trabajo, al tiempo que suelen determinar la aparición de otros Acuerdos específicos o "sobre materias concretas" relativas a la política de empleo en sentido amplio. En este sentido, el IV Acuerdo andaluz de concertación fue un exponente relevante de esta incidencia de la concertación sobre empleo en la negociación colectiva, determinando un proceso de proyección "en cascada" en el ámbito de la negociación colectiva sectorial y de empresa. En el marco de este Pacto por el Empleo y el Desarrollo de Andalucía los agentes sociales suscribieron un Documento de Recomendación sobre Negociación colectiva y Medidas de Fomento de Empleo en el ámbito de la Comunidad Autónoma de Andalucía, para dar adecudada aplicación al Acuerdo Interconfederal para la Estabilidad en el Empleo de 1997, de ámbito estatal. Es evidente que muchos de las materias objeto de concertación en el V Acuerdo se traducirán en compromisos específicos en el marco de la negociación colectiva de Andalucía, como prueba el que la revalorización de la negociación colectiva constituya uno de los aspectos más señeros del $\mathrm{V}$ pilar estratégico del Acuerdo de Concertación, relativo al enriquecimiento y potenciación de

20. La creación de más empleo y de carácter más estable se configura como objetivo principal en la acción concertada entre el Gobierno andaluz y los agentes sociales y econónicos para avanzar hacia la meta del pleno empleo, para lo que busca la definición de una estrategia unitaria e integrada que debe ser impulsada e institucionalizada a través del Nuevo Servicio Público de Empleo de Andalucia. La novedad más importante incluida en el IV acuerdo fue la elaboración del Plan de Desarrollo Regional (PDR). LOS agentes sociales, por primera vez, podrián influir en las políticas de empleo y económicas de la Junta al permitírseles su participación en el diseño del PDR dentro del Marco de Apoyo Comunitario 2000-2006. El PDR contará de una inversión pública de 3,6 millones de pesetas, 2,5 de ellos financiados por la UE. Esta idea, escasamente concretada en el periodo de vigencia del Acuerdo anterior, vuelve a ser recogida en el V Acuerdo, Eje IV, Planificación económica y políticas sectoriales. 
los instrumentos de negociación ${ }^{21}$. Para este nuevo paradigma de concertación social, bautizado como "concertación de reajuste industrial permanente. la negociación colectiva,se revela como uno de los instrumentos más decisivos para favorecer la creación de empleo, tanto en el sector privado como en el sector público.

Esta opción se revela, por otro lado, plenamente conforme con el favor que el diálogo social y la negociación colectiva han asumido en la definición y actuación de las políticas socio-económicas comunitarias, en particular en orden a reordenar las condiciones de funcionamiento de los mercados de trabajo correspondientes a los Estados miembro. A tal fin, ha de recordarse que ael fomento del empleo, la mejora de las condiciones de vida y de trabajo, a fin de conseguir su equiparación por la vía del progreso, una protección social adecuada, el diálogo social, y desarrollo de los recursos humanos para conseguir un nivel de empleo elevado y la lucha contra las exclusiones" (art.136 TCE), constituyen objetivos expresos de la nueva «Constitución Social Europea", que tiene en la afirmación del derecho al empleo y del derecho a na renta mínima de inserción dos pilares claves del proyecto de reconstrucción del modelo social europeo. La nueva centralidad del empleo en el plano de las políticas sociales y económicas, por tanto en el plano del Derecho Social Comunitario, y el protagonismo del diálogo social en la realización de estas políticas y de este derecho, hace del Derecho del Empleo Comunitario un Derecho crecientemente convencional, sin perjuicio del papel impulsor y promotor de las Directivas. La trilogía de Acuerdos Marco, realizados y proyectados, en materia de contratación - trabajo a tiempo parcial, contratos de duración determinada y empresas de trabajo temporal-, son un claro ejemplo de esta revalorización del papel de los interlocutores sociales ${ }^{22}$.

III. El EMPLEO COMO OBJETO DE NEGOCIACION COLECTTVA: VIEJAS Y NUEVAS CLÁUSULAS CONVENCIONALES DE EMPLEO.

\section{La política de empleo en la negociación colectiva: un cuadro general de las principales} cláusulas incorporadas a los convenios.

Pero si el empleo no sólo se convierte, como hemos visto, en objeto preferente del nuevo modelo de intercambio socio-político (=técnica de concertación=), sino que constituye uno de los capítulos crecientemente engrosados de la negociación colectiva, se precisa ya un análisis detenido y sistemático, descriptivo y crítico, de las denomina-

21. La generación y consolidación del empleo, así como la competitividad de las empresas, requiere, a juicio de los firmantes del $\mathrm{V}$ Acuerdo de Concertación, la corresponsabilidad de los agentes económicos y sociales en el desarrollo de las relaciones laborales.

22. Un análisis reciente, sobre la diferenciación de las dos formas de diálogo social europeo, el diálogo social-participación social (art.138 TCE), y el diálogo social-negociación colectiva autónoma (art.139 y 138:4 TCE), aunque perfectamente comunicables entre sí, en MONEREO, J.L.Concertación...op.cit.pags.123 y sgs. 
das cláusulas sobre empleo, respecto a las cuales no se ha conducido todavía en nuestra doctrina un análisis suficientemente pormenorizado y exhaustivo, sin perjuicio de contar con algunas contribuciones pioneras, de carácter parcial pero de gran utilidad. En las páginas que preceden se puso de manifiesto la importancia actual de los problemas del empleo y su influencia en la negoción colectiva. El desempleo masivo supone un drama personal, pero también una baja productividad industrial $y$ un uso ineficaz del capital industrial y social.

Desde el punto de vista metodológico, es preciso delimitar previamente lo que haya de entender por política activa de empleo, para después pone de relieve el lugar que en ese campo corresponde a la negociación colectiva con extraordinaria frecuencia hacia referencia expresa la "política de empleo" como contenido de los convenios y acuerdos colectivos. La política activa de empleo remite los distintos mecanismos de intervención en el mercado de trabajo, que tienen por finalidad la creación de empleo o la reducción del desempleo respecto de aquellas personas que se hallan en disposición de trabajar. Las políticas activas de empleo comprenden un conjunto heterógeneo de acciones que tienen por misión, como dice el art.1 LBE, en realidad el único efectivamente vigente - pese a su vigencia formal - de esta ahora ya obsoleta y desfasada Ley, mantener o reconstruir un equilibrio permanente entre la "oferta" y la "demanda de empleon, ya tanto en "sus aspectos cuantitativos" cuanto, y sobre todo, en sus aspectos "Cualitativos" ${ }^{23}$. La contribución que está en condiciones de prestar la negociación colectiva para conseguir este objetivo de equilibrio no encuentra dificultad formal alguna, a tenor del art.37.1 CE y 85 LET.Ello es así a pesar de la eficacia relativa de la política de empleo llevada a cabo desde instancias privadas, como una respuesta deliberada a las exigencias actuales del mercado y de los problemas del empleo.

En este sentido, entre los múltiples criterios clasificatorios, y aún conscientes de la dificultad de encuadrar una gran diversidad de cláusulas que tienen incidencia, directa o indirecta en el ámbito del empleo, se puede seguir aquella ordenación que diferencia en atención al objetivo perseguido. A saber ${ }^{24}$ :

a) las que pretenden asegurar o garantizar el "mantenimiento" del volumen empleo existente en una determinada empresa o sector.

b) las que se ocupan del aumento o mejora de la tasa de empleo existente, con vista a contribuir a la creación de empleo neto (=cláusulas de fomento del empleo=).

23. El art. 2 LBE, concreta los objetivos específicos de la política de empleo que se deducen ya de la misma definición legal formulada en el art.1 de ese cuerpo legal. En términos análogos la Recomendación núm. 176 OIT, sobre el fomento del empleo y la protección contra el desempleo (1988).

24. Para un criterio clasificatorio algo diferente, más tradicional, vid. GARCíA BLASCO, J..Los compromisos sobre empleo en la concertación social y el papel de la negociación colectiva". En AA.VV. (coord: A. Ojeda Avilés). La concertación social tras là crisis. Barcelona.Ariel.1990. 
c) aquéllas orientadas a facilitar la estabilidad del empleo existente (=garantías de estabilización del empleo=).

d) las dirigidas a intercambiar los incrementos de productividad por la reducción/ reordenación el tiempo de trabajo como vía para mejorar las tasas de empleo (=cláusulas de reparto solidario del empleo=).

e) las orientadas prevalentemente a la gestión flexible de la dimensión ocupacional de la empresa o sector de actividad concernidos (= cláusulas de reestructuración o modernización de plantillas=).

f) cláusulas de transparencia del volumen, composición y funcionamiento de las relaciones de empleo

Aunque la presencia de unas y otras en la negociación colectiva, sectorial y de empresa, es altamente desigual, en todo caso se pone de relieve un continuo crecimiento de las mismas, que está sirviendo para renovar, aunque con extremada lentitud, los tradicionales contenidos de la política convencional de empleo, si bien siguen dominando las cláusulas que se orientan, bajo diferentes modalidades, al mantenimiento del empleo existente, siendo aún escasas las que expresan un compromiso firme de creación de empleo neto. La autodenominadas colectivamente, "políticas de empleo" suelen ser en muchos casos medidas defensivas, no ofensivas de política activa que verdaderamente se encamine a la creación de empleo ${ }^{25}$.

No es extraño, pues, la constatación del carácter minoritario de las cláusulas específicas de creación neta de empleo en el marco de la negociación colectiva. En muchos casos se trata de regulaciones sobre las modalidades de contratación laboral, políticas de jubilaciones (en sentido amplio), asociadas frecuentemente al tratamiento de la empresa en crisis o en proceso de reestructuración del sistema productivo empresarial, precisamente porque se trata de un ámbito donde la negociación colectiva puedé demostrar su mejores cualidades de instrumento útil y flexibilidad para el diseño y aplicación de medidas específicas que atiendan a las necesidades de composición de los intereses implicados (=política de contratación y gestión flexible de la plantilla (excedente) $=)^{26}$. Por lo demás, la

25. Sobre el contenido actual de la negociación colectiva, es últil el informe de síntesis elaborado por el CES: Memoria sobre la situación socioeconómica y laboral de España en 1999. Madrid. CES. 2000. En sentido análogo, de este mismo Organismo de Concertación institucionalizada, vid. «El Empleo en la Negociación Colectiva Española. Observatorio de Relaciones Industriales, CES, n.32, 2000.

26. La llamada "política de empleo" en el cuadro de la negociación colectiva a menudo puede ser asimilada a la "política de recursos humanos", sin verdadera capacidad para crear empleo. cfr. OJEDA AVLES,A.: "El contenido de la negociación colectiva en materia de empleo y ocupación: las cläusulas sobre empleo. En AA.VV.: Empleo, contratación y negociación colectiva. Madrid. MTSS. 1999. pág.139. 
política de creación de empleo, la figura de los contratos de inserción, las medidas dirigidas a la exclusión social, son impensables sin la intervención decisiva de los poderes públicos. Podría pensarse, quizás, en que existe un límite intrínseco en el instrumento: los convenios colectivos no son los instrumentos más adecuados para realizar una política de creación de empleo. Ésta dependería básicamente de la política económica y de los recursos allegados desde las AA.PP. La autonomía colectiva carecería de los factores base de poder necesarios para realizar esa función de ser fuente de creación directa de empleo. En la práctica, la negociación colectiva suele asumir todo lo más un papel marginal o de acompanamiento de las políticas públicas de empleo. Por otra parte, no favorecería a la función "empleativa" el relativo declive de los convenios sectoriales, pese al intento de recuperación por el AINC, que son los que permitirían construir circuitos especiales de colocación en los sectores de actividad económica, si bien son los empresariales lo que están en mejores condiciones de comprometerse a fijar garantías de nueva contratación por su mayor proximidad con la realidad de la empresa ${ }^{27}$. No obstante, conviene no perder de vista las nuevas funciones del convenio colectivo, tanto en su dimensión de gestión productiva cuanto de distribución de riqueza, no sólo respecto de salarios sino también en materia de condiciones de empleo: la negociación es un útil instrumento para la canalización de compromisos firmes y directos de empleo aprovechando las políticas públicas de promoción (el Derecho del empleo como instrumento de distribución bilateral o negociada de fondos públicos).

En el ámbito empresarial, interesa llamar la atención sobre el papel fundamental que desempeñan nuevas unidades de negociación, como los grupos de empresas. Este tipo de convenios contemplan al grupo como un mercado interno de trabajo, a efectos de la movilidad laboral de los ex-trabajadores, de unificación de la política de recursos humanos (sistemas de formación, sistemas de encuadramiento profesional, sistemas salariales, etc.) y de tratamiento de los excedentes de plantilla a través de una política global de bajas incentivadas y de prejubilaciones consensuada con los representantes de los trabajadores ${ }^{28}$.

27. Sin perjuicio de que sí suelen contener referencias a la política de prejubilaciones con acompañamiento de medidas de nueva contratación laboral. Con los correctivos pertinentes podría haberse aprovechado la experiencia de los Fondos de Promoción de Empleo de las reconversiones industriales, que unificaban un conjunto de medidas de tratamiento de los excedentes de personal, tales como las prejubilaciones, -jubilaciones anticipadas", protección extraordinaria por desempleo y circuitos específicos de colocación.

28. De particular importancia las cláusulas de movilidad y recolocación. vid. MOLINA NAVARRETE, C. La regulación juridico-laboral de los grupos de empresas: problemas y soluciones. Granada.2000. Comares. 


\section{Nuevos usos de viejasu formas de gestión convencional del empleo: Política de empleo,} prejubilación y negociación colectiva.

a) La medida de prejubilación como contenido específico de la negociación colectiva.

La "prejubilación" ha sido una medida muy importante en las dos últimas décadas en los procesos de reestructuración y modernización de las empresas, como conjunto de mecanismos "no traumáticos de expulsión de la mano de obra excedente. Inicialmente prevista como excepcional pasará, en gran medida por mor de la autonomía colectiva, como una medida normalizada jurídicamente en el plano socio-económico, como puente o vía de transición entre el cese anticipado en el trabajo y el cumplimiento futuro de la edad normal pensionable ${ }^{29}$. Esta medida se inserta en un cuadro de medidas pensadas para la expulsión "indolora" y no "desestabilizadora" del orden social de la mano de obra madura:

* la jubilación anticipada (producida antes de la edad legal ordinaria de jubilación conforme a la Seguridad Social, entre los sesenta y los sesenta y cinco años; la cual es de naturaleza individual), utilizada a menudo como medida relacionada con el fomento del empleo ${ }^{30}$, que, como aquélla, presupone que el sujeto percibe la pensión de jubilación del sistema de Seguridad Social antes del cumplimiento de la edad normal legalmente prevista;

29. Sobre los orígenes de esta medida en los procesos de reconversión industrial, vid. MONEREO PÉREZ, J.L.: Las reconversiones industriales en el Derecho del Trabajo. Granada (Universidad). 1988.

30. Las cláusulas sobre jubilación anticipada, total o parcial, son muy frecuentes en la práctica de la negociación colectiva en nuestro país, aunque cabe advertir que con dicha denominación los convenios colectivos regulan una amplia diversidad de figuras de extinción contractual vinculada a una edad determinada. Así, por ejemplo la jubilación de edad reducida (jubilación conforme a la Seguridad Social a los 64 años). Esta modalidad de anticipación de la edad de jubilación (jubilación especial) aparece en Convenios Colectivos como el de Pastas alimenticias de Cataluña (industrias de), Res.18. X.1994, D.O.G.C. 26-IV-1995. I.L.2878. Art.26. Se trata, pues, de una norma de reenvio a acuerdo individual. Se suele vincular a una política de fomento del empleo. También el CC del sector de Turrones y mazapanes (fábricas de). Res.30-X-1992, BOE. 20-XI-1992. I.L.6353. Disposición Adicional Quinta. En realidad desde el punto de vista de la lógica específica del sistema de Seguridad Social, la anticipación de la edad de jubilación como consecuencia de medidas relacionadas con el fomento del empleo afecta a través dos modalidades: la jubilación especial a los 64 años (Disposición Final 40 LGSS), para trabajadores cuyas empresas sustituyan a aquellos trabajadores que acceden a la jubilación y simultáneamente al cese en el trabajo, por otros trabajadores desempleados (es frecuente que, al amparo de la Diposición Décima del ET, los convenios colectivos configuren esta modalidad de jubilación como una -jubilación forzosa. por razones de fomento del empleo); y la jubilación parcial (art.166 LGSS) a través de un contrato de relevo. Vid. PANIZO ROBLESJ.A.: -El final de una polémica: las nuevas reglas sobre anticipación de la edad de jubilación (a propósito del Real Decreto-ley 5/1998, de 29 de mayo)n, en Revista del Ministerio de Trabajo y Asuntos Sociales, núm.14 (1999), págs.55 y sigs; MOLINA NAVARRETE, :-..... Sobre las previsiones de la negociación colectiva en materia de edad, véanse los ensáyos de LÓPEZ GANDIA J.: Jubilación y política de empleo, en RSS, núm.36 (1987). Una interesante perspectiva de conjunto sobre la anticipación del momento de la jubilación puede hallarse en RODRfGUEZ-PINERO,M.: LLa flexibilidad de la edad de jubilación en el sistema español de pensionesm, en AA.VV.: Europa en el movimiento demográfico. Los sistemas de pensiones y la evolución demográfica, Madrid, MTSS, 1993, págs.247 y sigs 
* la jubilación parcial (descle los 60 años), y cuya finalidad es el fomento del empleo, siquiera a tiempo parcial, de trabajadores en situación legal de desempleo; y, en fin, * la prejubilación, que no es jubilación en sentido estricto, porque hay anticipación en la percepción de la pensión de jubilación de la Seguridad Social, y que constituye una situación puente entre el cese prematuro y definitivo en el trabajo y el acceso a la jubilación ordinaria (el período normal es entre los 52 y los 65 años, pero también puede ser menor en algunos supuestos de reestructuración de mano de obra difícilmente recualificable).

En realidad todas estas modalidades de anticipación en el trabajo y/o de la edad de jubilación están actualmente "tintadas" por orientaciones de política de empleo. Así la prejubilación supone un modo dinámico de separar al trabajador activo de la relación laboral y de vincularlo a la jubilación ${ }^{31}$. En el plano de la técnica protectora, su naturaleza es híbrida, pues se sitúa como técnica específica intermedia entre la protección por desempleo y la protección de vejez. La medida de prejubilación asume un carácter colectivo, a diferencia de la jubilación anticipada que presenta un carácter individual ${ }^{32}$. Ha sido esta una medida especialmente utilizada para la reclucción drástica de las plantillas, tanto en los tradicionales procesos de reconversión industrial. como en los renovados de crisis económica y/o reestructuración organizativa y tecnológica ( por tanto en momentos de bonanza empresarial) que fundamentan la expulsión de mano de obra madura. He aquí, que la prejubilación convencional es utilizada por las empresas, no sólo en crisis o en dificultades, como un instrumento jurídico-económico para facilitar las reestructuraciones productivas a través del recurso a la extinción contractual por prejubilación, lo que permite a los trabajadores afectados beneficiarse de una protección superior a la que proporcionaría un despido ordinario por crisis o circunstancias objetivas. La medida suele tener una financiación mixta (a cargo del Estado mediante el sistema de protección por desempleo; y a cargo de las empresas, a través de aportaciones económicas adicionales a la cotización ordinaria de Seguridad Social). Su utilidad específica reside en suprimir empleos disfrazando al parado en (pre)jubilado total o parcial.

31. Vid. sobre la contingencia de prejubilación LÓPEZ CLMBRE, L.: La prejubilación, Madrid, Civitas, 1998. 32. Adviertase que la prejubilación puede garantizarse a través del sistema de planes y fondos de pensiones. La regulación legal prevé el aseguramiento de la "jubilación o situación asimilable" y también es freuente en la negociación colectiva. Así, IX Convenio colectivo de la empresá organización nacional de ciegos españoles (ONCE) y su personal (Res.29 mayo 1998, BOE, núm.150, 24 junio 1998), establece. en su ar.67.4, que .Las contingencias cubiertas por «Oncepensión I", son: Jubilación o situación asimable, gran invalidez o invalidez permanente total o absoluta para todo trabajo en la ONCE: fallecimienton. El marco legal actual, aunque deficiente en muchos aspectos, admite el aseguramiento de la prejubilación como contingencia protegida en el sistema integrado de planes y fondos de pensiones. Asi los artículos 8.6.a) LPFP y 16.2.a) RPFP, contemplan entre las contigencias protegidas a través de dichos regímenes de previsión privada la jubilación o situación asimilable.. 
Los procesos de reestructuración permanente y el aumento del paro están provocando la expulsión sistemáticà de la mano de obra madura a través del expediente fácil, pero muy costoso, de las prejubilaciones. Es éste en gran medida un uriesgo fabricadon por el modelo de desarrollo de la sociedad contemporánea en el sentido de Beck $^{33}$. Esas medidas son funcionales para la reorganización permanente de los aparatos productivos, siendo el sistema de protección social, y en particular de Seguridad Social, un instrumento de regulación de los mercados en estrecha colaboración con las políticas de empleo ${ }^{34}$. No entra en juego sólo la lógica específica de la protección social, sino también la lógica específica la racionalización jurídico-económica: no se puede ignorar aquí la lógica deliberada de racionalización jurídica de los recursos humanos realizada por las empresas en la busqueda de las "plantillas acordeón", fácilmente adaptables a la variables de los mercados y las variadas estrategias empresariales ${ }^{35}$.

Una fotografía de la realidad social de las prejubilaciones en nuestro sistema de relaciones laborales y de protección social puede ayudar a comprender la coexistencia contradictoria entre esas dos lógicas, dando lugar a un conflicto de lógicas inserto en el mismo sistema regulador. Por otra parte, esa misma realidad social de las prejubilaciones permite comprender su importancia en relación con el sistema de negociación colectiva en España, como ha ocurrido también en la mayoría de los países europeos. Hasta tal punto es así que las instancias políticas de la Unión Europea han llamado la atención sobre el excesivo coste económico que supone para los Estados este tipo de medidas protectoras de base y motivación laboral, aconsejando una limitación más estricta de las mismas ${ }^{36}$. En efecto, en la práctica se comprueba el dualismo de la prejubilación como medida al servicio de las regulaciones de empleo (instrumento de regulación jurídica del empleo) y como instrumento de protección social de los trabajadores excedentes (generalización de la experiencia de las reconversiones industriales).

Amparándose en la normativa de los Expedientes de Regulación de Empleo (ERE), y en la cobertura legal de las razones "técnicas, organizativas o de producciónn, las grandes empresas, sobre todo, aunque no sólo, en los procesos de fusión, ajustan sus plantillas dando la baja anticipada a todos los trabajadores maduros que están más próximos a la edad de jubilación ordinaria. El problema es que estos "ajustes" no traumáticos de plantilla se realizan mediante la asunción por el sistema de Seguridad

33. Vid, BECK,U.:La sociedad del riesgo. Barcelona. Paidós. 1998.

34. Véase MONEREO PEREZ J.L.: El sistema de protección por desempleo, Valencia, Tirant lo blach, 1997.

35. Sobre el sentido político-jurídico de las medidas de flexibilidad laboral en los prócesos de ajuste permanente del aparato productivo, véase MONEREO PÉREZJ.L.: Las reconversiones industriales en el Denecho del Trabajo, Granada (Universidad), 1988.

36. Vid.infra, en este mismo apartado. 
Social del coste principal cle esta medida de gestión racionalizaclora de la dimensión ocupacional de la empresa. Al margen del coste de las indemnizaciones o de los complementos de la pensión que puedan pactarse en la mesa de la negociación con los sindicatos, la empresa cancela sus compromisos con el Inem desde que hace efectivas estas prejubilaciones "masivas" "."

Se produce así una transferencia de cargas o costes del funcionamiento del mercado laboral a la Seguridad Social, poniendo de relieve cómo ésta está asumiendo una función esencial en auxilio de los mercados. Uin papel "activo" que con harta frecuencia es ignorado desde las corrientes de pensamiento situadas en la llamada política de la oferta" que contempla la vertiente exclusivamente nominal de los gastos de protección social y no la multiplicidad de los factores causantes del gasto público en materia social. Todo ello confirma que no estamos aquí ante una simple negociación colectiva de establecimiento de medidas de protección social, sino ante una negociación colectiva cualificada por su carácter condicionado al intervencionismo público que hace viable económicamente las medidas aprobadas. En cierto modo ello convierte a la negociación colectiva de reestructuración (con medidas de acompañamiento social) en una negociación esencialmente "concertativa" con el poder público, sin el cual no podrían tener éxito los compromisos en la misma contraídos por los agentes sociales. Es una negociación "político-social", híbrido entre la negociación colectiva bilateral típica y la concertación social tripartita. Sin la colaboración activa del poder público no se podría realizar la base del acuerdo colectivo de restructuración productiva.

Desde una perspectiva jurídico-crítica, cabe señalar que hoy en día las prejubilaciones son una medida contestada, sobre todo por su aplicación con carácter indiscriminado para todo tipo de empresas que realizan procesos de reestructuración con independencia si presentan o no beneficios. Por lo demás, las instancias políticas comunitarias ya han mostrado su preocupación en repetidas ocasiones ante la práctica general que se sigue entre los Estados de la Unión Europea sobre las

37. Es el caso de ajustes no traumáticos que se realizan en mineria (sujeta aún a planes de reestructuración industrial; ej. el Gobierno aprobó el día 28 de mayo de 1999, 41 nuevos proyectos de reactivación de las comarcas mineras que supondrán una inversión de 7.903 millones de pesetas), en el sector bancario ( ej. Plan de prejubilaciones en el Banco Atántico, -El País., 28.5.1999) o en grandes empresas, como Telefónica o Tabacalera. En el fondo existen dos vias jurídico-económicas para cubrir los costes laborales del ajuste de plantilla: junto a la transferencia de cargas a la Seguridad Social, en el caso de las empresas públicas, se dan también ayudas directas. El día 28 de mayo de 1999, la Sociedad Estatal de Participaciones Industriales (Sepi) amplió en 41.000 millones de pesetas el capital social de Babcock Wilcox, grupo vasco de bienes de equipo. De este importe, 16.000 millones se destinarán a cubrir obligaciones laborales del pasado, que tuvieron que contabilizarse como resultados extraordinarios negativos en el ejercicio de 1998 y que fueron la causa de que las pérdidas finales de la compañía se elevaran a 18.492 millones. Los restantes 25.000 millones de pesetas de la ampliación de capital se destinarán a acometer una reestructuración de la compañía, con el fin de solventar su actual exceso de dimensión. que penaliza su cuenta de resultados, según la Sepi. 
prejubilaciones normalizadas como técnica de expulsión de los excedentes de personal, que ponen en riesgo por causas "externas" a su función protectora típica la financiación de los sistemas de protección social y especialmente la más importante, la rama de pensiones. Se llama la atención sobre la carga excesiva para los sistemas de protección social que supone el incumplimiento sistemático de la edad legal de jubilación ordinaria. Se trata de una utilización "abusiva de la medida de prejubilación (y de jubilaciones anticipadas en términos generales o atécnicos), tanto más inaceptable en sectores con importantes beneficios, como el financiero.

Cabría inquirir sobre el hecho de que una medida tan problemática como la prejubilación, a pesar de sus inconvenientes haya tenido un indudable éxito dentro de las políticas de reestructuración de las plantillas. Es posible pensar, como se verá de inmediato, que la técnica en sí sea útil, y que el aspecto más problemático resida, en cambio, en el actual modelo normativo de regulación de la prejubilación como contingencia protegida. No cabe duda que la medida de prejubilación ha permitido conciliar en vía negocial la pluralidad de los intereses en presencia en los procesos de reestructuración productiva. La medida fue alentada por el poder público, a pesar de su coste económico por las ventajas que se obtienen desde el punto de vista de la pacificación social y la legitimación político-social. La prejubilación ha sido una medida amortiguadora de los conflictos generados por los procesos de reorganización productiva. El poder público obtiene la paz social necesaria para la gobernabilidad ${ }^{38}$. Los agentes sociales han visto en ella una vía para la modernización y la adaptación competitiva de las empresas y un mecanismo más indoloro que el despido por necesidades de funcionamiento de la empresa para resolver el problema de los excedentes de personal ${ }^{39}$. No se olvide que es un proceder generalizado la aprobación de los programas de prejubilación a través de planes sociales consensuados con los representantes de los trabajadores.

Por lo demás, la prejubilación puede ser una medida útil y funcional para el fomento del empleo de trabajadores desempleados, aunque con el coste social de un cese anticipado de los trabajadores de edad madura. Hay preciso decir que existe una práctica, no suficientemente generalizada, de vincular en la negociación colectiva de reestructuración el programa de prejubilaciones con compromisos empresariales de celebración de nuevos contratos $^{40}$. Existen también en España

38. No debe olvidarse que la utilización sistemática de esta medida tiene su base histórica en los procesos de reconversión industrial. Sobre ese componente político de la medida de prejubilación en los origenes, que sigue subsistiendo aún, si bien bajo nuevas formas, vid.MONEREO PÉREZJ.L.: Las reconversiones industriales en el Derecbo del Trabajo, Granada (Universidad), 1988.

39. La prejubilación se muestra al trabajador como una opción de presente beneficiosa frente a un futuro desconocido. cfr. LÓPEZ CUMBRE,L.: La prejubilación,op.cit., pág:51.

40. Téngase en cuenta la experiencia francesa del Acuerdo de 6 de septiembre de 1995, sobre prejubilación y contratación compensatoria. Vid.supra. 
pactos y convenios colectivos que establecen esa vinculación cuando se trata de jubilación forzosa ${ }^{41}$. La negociación colectiva puede, pues, fijar la edad de retiro laboral del trabajador, sin perjuicio del respeto a la normativa reguladora de la pensión de Seguridad Social, puesto que sobre el derecho a la pensión pública no existe disponibilidad colectiva ${ }^{42}$.

A menudo, sin embargo, los convenios colectivos imponen una jubilación forzosa incondicionada a los 65 años $^{43}$, aunque son varios los que contienen la exigencia de no amortizar los puestos de trabajo de los trabajadores jubilados ${ }^{44}$. Sólo cuando se fija la edad obligatoria vinculada a la no amortización del puesto de trabajo ocupado por el trabajador que se jubila se puede decir que la medida de jubilación forzosa constituye una medida que contribuye al reparto del empleo, como auténtica medida de fomento de empleo. Todo lo cual ha sido considerado lícito por una jurisprudencia flexibilizadora del Tribunal Supremo de los requisitos originariamente exigidos por el Tribunal Constitucional. En ella se establece la doctrina de que

41. Cuyo carácter en muchos casos incondicionado en la negociación colectiva puede contradecir la doctrina del Tribunal Constitucional desde la STCo 22/1981, de 2 de julio, pasando por las posteriores 58/ 1985, 2 de julio, 95/1985, de 30 de abril, y 111 a 136/1985, de 11 de octubre. Véase también, desde otro punto de vista, la STCo $207 / 1987$, de 22 de diciembre.

42. La Disposición Adicional 100 LET ha sido recientemente derogada por el RD-Ley 5/2001. En una perspectiva más respetuosa con la idea incentivar la permanencia toluntaria del trabajador de edad madura es -como manifestación de un cambio de actitud de política del Derecho- la Disposición Adicional Vigésimosexta de la LGSS (añadida conforme a lo dispuesto en el art.12 de la Ley 24/1997, de 30 de diciembre, de Medidas Fiscales, Administrativas y del Orden Social), según la cual .El Gobiemo podrá otorgar desgravaciones, o deducciones de cotizaciones sociales, en aquellos supuestos en que el trabajador opte por permanecer en activo, una vez alcanzada la edad de sesenta y cinco años, con suspensión proporcional al percibo de la pensión. La regularización de los mismos se hará previa consulta a las organizaciones sindicales y asociaciones empresariales más representativas.

43. V.gr., Pastas Alimenticias (fabricación de), Res.30.X.1998. BOE 16-XII. 1998. I.L.4909, art.35, relativo a la -Ayuda por jubilación, jubilación anticipada y jubilación forzosan. Igualmente, Acuerdo marco estatal de pasteleria, confiteria, bolleria, reposteria y platos cocinados. Res.13-II-1996, BOE. 11-III-1996. I.L.1025. art. 30; Productos dietéticos y preparados alimenticios de Cataluña. Res.6-VII-1998. D.O.G.C. 15-IX-1998. 1.L.3825. Art.51.2; Convenio colectivo de ámbito estatal para el sector de mantenimiento de cabinas, soportes y teléfonos de uso püblico. Res.29-VII-1997. BOE.15-VII-1997. IL.3708. Art.24..

44. Las cláusulas de no amortización de puestos de trabajo no generan relaciones postcontractuales ya que el empresario no mantiene relación alguna con los ex-trabajadores, sino que asume un compromiso derivado del convenio colectivo de proceder a cubrir el puesto de trabajo dejado vacante. Asi, por ejemplo, Artes Gráficas, manipulados de papel y cartón, editoriales e industrias auxiliares, Res. 5-II-1997. BOE. 20-III-1997. I.L.1239. Ar.6.4.7; Seguros y reaseguros (Empresas de). Res.17-XI-1998. BOE. 11.XII.1998. 1.L.4888, Art.63. Jubilación; Convenio colectivo general para las empresas concesionarias y privadas de aparcamientos devebículos. Res.23-II-1998. BOE. 11.III. 1998. 1.L.866. Art.61.Jubilación. Se prevé la jubilación obligatoria para facilitar el acceso al trabajo de personal joven desempleado. Ello implica una asunción de obligaciones postcontractuales, al quedar el empresario obligado a contratar un trabajador joven desempleado en sustitución del trabajador jubilado forzosamente. Así, por ejemplo, en la Comunidad Autónoma de Andalucía, donde distintos convenios colectivos (.Construcción* de la Provincia de Jaén, .Comercio para la 
los convenios colectivos no hạ de condicionar la jubilación forzosa a la no amortización de los puestos de trabajo de los trabajadores jubilados ${ }^{45}$. Según la doctrina del Tribunal Supremo es suficiente que la medida de jubilación forzosa permita garantizar la viabilidad o mantenimiento de empresas en dificultades, o cualesquiera análogas ${ }^{46}$.

Esta utilidad específica y el apoyo de los agentes sociales reflejan las dificultades de una transición de modelos de prejubilación, en un sentido correctivo al modelo actualmente vigente. No se trata de hacer desaparecer la medida, más que de suprimir se trataría de redefinir su función y los medios más idóneos de financiación real, con la indicación razonable de que el camino para ese rediseño es coherente que se realice a través del consenso. Por el momento se puede pensar en soluciones parciales. En el plano de la política social (de la lógica de protección social) deberá ponderarse la conveniencia de expulsar a una mano de obra madura en aras de un principio de flexibilidad laboral a menudo de muy dudosa racionalidad, y no sólo en términos de humanización del trabajo, sino también en términos de valorización de los recursos humanos afectos a la organización productiva. En el plano de la distribución de costes económicos de las prejubilaciones que sean acordadas: que todas las empresas $-\mathrm{o}$, al menos, las empresas en grave situación económica, y con pérdida continuadasque inicien un ERE abran una cuenta de ingresos en la Seguridad Social por el importe de las cotizaciones sociales que correspondería pagar hasta que los trabajadores afectados (prejubilados) alcancen la edad de jubilación (edad pensionable), que como

Alimentación" de la provincia de Jaén, -Almacenistas y Detallistas de Alimentación. de Sevilla, Convenio provincial de .Pastelería, Confitería y Despacho de etc.... de la provincia de Cádiz, y a nivel empresarial, el convenio U.T.E. Iberabón, S.A.,Edifesa y Aborgase, S.A.) establecen la edad obligatoria de jubilación a los 65 años, pero con el doble requisito de que el trabajador tenga cubierto el período mínimo de carencia exigido para obtener la prestación contributiva de jubilación y la empresa asuma el compromiso de efectuar contrataciones en sustitución de los jubilados. Datos al respecto, en CONSEJO ANDALUZ DE RELACIONES LABORALES: ‘La negociación colectiva en Andalucia. Memoria C.A.R.L.1998, Sevilla, 1999, págs.274 y sigs.

45. SS.TS 27 diciembre 1993, ar. 10011, y las anteriores de 27 octubre 1987, ar.7210 y ar.7211.

46. STS 29 octubre 1990 (A/7937). Una crítica a esa elaboración jurisprudencial en SASTRE IBARRECHE,R: -La jubilación forzosa por edad., en REDT, núm.43 (1990); VALDÉS DE LA VEGA, B.: Mejoras..., op.cit.,págs.126 y sigs., con referencia a la doctrina judicial referenciada en el texto. En relación a la autorización legal prevista en la Disp.Adicional 100 LET, el Tribunal Supremo tha minimizado...el concepto de política de empleo* respecto a la fundamentación jurídica de la jubilación forzosa, no exigiendo que el convenio establezca la cobertura del puesto de trabajo por un trabajador desempleado. Por lo demás, en los acuerdos de reorganización productiva las jubilaciones forzosas pactadas tienen su fundamento jurídico-positivo en el art.51 LET, el cual no impondría necesariamente una política de empleo alternativa, sino un plan social de tratamiento de los excedentes de personal. cfr. OJEDA AVILES,A.,MARIN ALONSO;I.: "Comentario al art.160 de la LGSS", en AA.VV. MONEREO PÉREZ,J.L.- MORENO VIDA,M.N. (Dir.): Comentarios a la Ley General de Seguridad Social. Granada. Editorial Comares. 1999. 
regla general es la de sesenta y cinco años (art.161.1,a) LGSS) ${ }^{47}$. A pesar de la sencillez de esta propuesta, es difícil que la medida de la apertura de la cuenta sea admitida (más bien será rechazada de plano) por algunos empresarios acostumbrados al desplazamiento de los costes de los excedentes de plantilla. Pero el objetivo mínimo puede ser persuasivo y cautelar: preparar un clima reformista dirigido a introducir los ajustes del sistema de protección en el marco de la renovación del pacto de pensiones ("Pacto de Toledo").

No se trata de postular la supresión de la medida de prejubilación, su normalización jurídica (su estabilización) refleja su configuración como un riesgo estructural y no meramente coyuntural relacionado con la vinculación del sistema público de protección social con el mercado de trabajo ${ }^{48}$. Pero también hay que tener en cuenta que el cese definitivo y anticipado de los trabajadores de edad avanzada es estructural como medida de expulsión indolora de personal excedente. Lo cierto es que a través de la técnica de prejubilación la negociación colectiva regula y condiciona la posición jurídica del trabajador prejubilado, en gran medida renovada respecto a los términos que se formularon en las últimas décadas. La regulación convencional de la prejubilación y señaladamente el deber empresarial de financiar la medida en una típica relación de previsión social voluntaria supone la pervivencia de una relación postcontractual (la prejubilación presupone constitutivamente la extinción del contrato de trabajo y se resuelve en la garantía de una renta sustitutiva o compensatoria del salario) entre el trabajador prejubilado y la empresa de procedencia. Se trata, pues, de una típica relación post-contractual cuyo marco regulador ordinario es la negociación colectiva. De lo que se trataría es de garantizar que la medida sea idónea para el fin perseguido, por un lado, y por otro, que sólo puedan "beneficiarse" de ella las empresas en situación de graves crisis económica.

Estamos, en definitiva, ante un modelo de gestión colectiva de la edad encaminada al fin fundamentalmente iuslaboral del tratamiento de los excedentes de personal $^{49}$. Esta finalidad esencialmente iuslaboral preordenada a la reestructuración del personal, no hace sino subrayar cómo en estos casos de vinculación directa con las políticas de empleo y de distribución del empleo actualmente existente la pensión de jubilación tiende a "convertirse en una pensión de retiro, que se paga a la edad en

47. Lo que sí asumen, de ordinario, las empresas son prestaciones complementarias de protección dispensada a través del sistema público por desempleo.

48. En este sentido LOPEZ CUMBRE,L.: La prejubilación, cit., pág. 49.

49. La prejubilación se caracterizaría, por tanto, como una "medida integrada en la estructura de los sistemas de protección social de los distintos ordenamientos, convirtiéndose con el tiempo en una medida estructural, que forma parte del sistema de relaciones laborales y que se ba consolidado como un mecanismo de flexibilización de la mano de obra en las plantillas. cfr.LÓPEZ CUMBRE,L.: La prejubilación, cit., pág.65. 
que el asegurado cesa efectivamente en su actividad" profesional, pasando más a un segundo plano la perspectiva de política de vejez ${ }^{50}$. Sin embargo, después del largo periodo de experimentación y del uso abusivo de la institución, ha resultado evidente la necesidad de proceder a un replanteamiento de la función económico-social de la prejubilación, habida cuenta de las disfuncionalidades que se han planteado. Estas disfuncionalidades se relacionan con el carácter muy discutible de fundar una "política de empleo" en una política de jubilación o de anticipación del cese en el trabajo; con los excesivos costes que plantea para el sistema de Seguridad Social, que acaba socializando los costes de personal de las grandes empresas, a menudo en situación no crítica; con la dificultad evidente de conciliar una medida que entraña un importante coste económico con una "empresa en crisis" grave; y, en fin, la misma orientación de las políticas de Seguridad Social a prolongar la edad de jubilación para equilibrar la situación financiera del sistema, que hace más reacio al poder público para seguir promodiendo el retiro de la población activa de edad madura.

Nuevamente la cuestión seguramente resida en poner límites a los abusos en su utilización y en una modificación del reparto del coste de financiación de las medidas de edad en apoyo de las políticas de mercado. Es necesario potenciar la perspectiva de vejez como núcleo de la pensión de jubilación evitando que ésta sea un mero elemento instrumental para las políticas de mercado de trabajo, a pesar de que por razones coyunturales las medidas de anticipación de la edad, incluso por vía forzosa en convenio colectivo, siguen siendo utilizadas por las ventajas que proporcionan para las empresas en reestructuración y para los propios trabajadores ${ }^{51}$. Sin embargo esta persistencia de un uso excesivo de las medidas de edad, por razones meramente coyunturales, no es coherente con la garantía del equilibrio financiero que se postula en el llamado "Pacto de Toledo ${ }^{52}$.

50. Véase HOLZMANN,R.: -Las relaciones entre la política de seguridad en la vejez y la política del mercado de trabajo, RSS, núm.33 (1987).

51. Véase HOLZMANN,R.: -Las relaciones entre la política de seguridad en la vejez y la política de mercado de trabajo, $R S S$, núm.33 (1987). Sobre la necesidad de recuperar la utilidad específica originaria de la protección de vejez (retorno a los fundamentos histórico-jurídicos de la figura, pero reformulando la noción de vejez atendiendo a los actuales niveles de esperanza de vida) y el problema de la edad pensionable y la evolución de la política de edades, véase el completo estudio de MALDONADOJ.A.: La pensión de Jubilación, Tesis Doctoral Inédita, Granada, 1999, págs.250 y sigs., donde se critica la utilización desviada y desnaturalizada de la jubilación no tanto como una institución de previsión, sino principalmente como un instrumento de la política de empleo. También LOPEZ CUMBRE,L.:®Anticipación de la edad de jubilación. El confuso tratamiento jurídico de las jubilaciones anticipadas", en Tribuna Social, núm.94 (1998); SALVADOR PÉREZ,F.:-La racionalización de la pensión contributiva de jubilación", en CRL, núm.12 (1998).

52. El propio legislador persiste en cierta medida en esa dirección de política jurídica de facilitar y promover la anticipación de la edad de jubilación más allá de la edad ordinaria, al rebajar la jubilación parcial a los 60 años en virtud del RD. 144/1999, de 29 de enero. No obstante, es preciso tener en cuenta en este supuestos concreto que la medida tiene la otra faz de incentivar la permanencia en activo del trabajador que se jubila parcialmente. 
Deben potenciarse los sistemas de jubilación flexible, dentro de un determinado margen de edad ${ }^{53}$, por un cúmulo de razones que van desde el mismo interés del sujeto hasta el mantenimiento de los equilibrios financieros del sistema de Seguridad Social. Lo que no puede admitirse es que se siga asentando una política de empleo en una política de anticipación de la edad de jubilación total (frente a las virtualidades de la jubilación parcial que admite la compatibilidad entre pensión contributiva y trabajo profesional), tanto más por la irresponsabilidad que supone incentivar la jubilación ante una marcada tendencia hacia el envejecimiento de la población activa en los países desarrollados.

Esta tendencia a restringir la prejubilación por sus efectos disfuncionales es apreciable en la mayoría de los países europeos y advertida, como se verá después. hace más de una década en algunos prestigiosos informes realizados en Europa, como significativamente en el Informe sobre "La flexibilidad de la edad de jubilación", Consejo de Europa, Estrasburgo, 1989. Este Informe contenía una advertencia razonable al reclamo de la pre-jubilación como medida de política de empleo y de política de protección social: "Tales medidas pueden justificarse de un solo modo, a saber: sobre una base voluntaria (real), y como expediente temporal. para evitar una rebaja verdaderamente irreversible de la edad de jubilación. Pero, desde nuestra óptica, dichas medidas deberían situarse claramente fuera del sistema de las pensiones. que debe tratarse a todos los asegurados en pie de igualdad: sólo pueden corresponder al mundo de las relaciones industriales y concretadas en convenios colectivos". Esta advertencia ba sido razonable, pero en la práctica no cumplida en las experiencias nacionales. Sin embargo, el propio Consejo de Europa manifestaba las contradictorias posiciones respecto a las virtualidades de las pre-jubilaciones. Así en el "Informe sobre la Seguridad Social en una sociedad cambiante." (Consejo de Europa, Estrasburgo, 1989) se aconsejaba facilitar las prejubilaciones (únicamente cuando estén agotadas las posibilidades de reinserción profesional) ${ }^{5 t}$.

En realidad, se ha producido un giro en las preferencias de política del Derecho sobre la prejubilación. La medida en sí fue concebida e impulsada por el poder público como una acción positiva incidente sobre el volumen de mano de obra, que perseguían la retirada anticipada del mercado de trabajo de trabajadores de edad madura, sea en procesos de reconversión industrial, sea en procesos ordinarios de reorganización del aparato productivo. La negociación colectiva sobre el empleo y la reestructuración se

53. En este sentido RODRÍGUEZ-PIÑERO,M.:-La flexibilización de la edad de jubilación y el sistema español de pensiones", en AA.VV.: Europa en el movimiento demográfico. Los sistemas de pensiones y' la
euolución demográfica, MTSS, Madrid, 1993; ALDONADOJ.A.: La pensión de Jubilación, Tesis Doctoral Inédita, Granada, 1999, págs.264 y sigs.; GONZALO GONZÁLEZ.B.: -El debate sobre la edad de jubilación en Europa", RSS, núm.42 (1989); Id.: "El debate actual para la reforma de las pensiones", $T L$, núm.40 (1996).

54. Ibidem, pág.157. 
había visto enmarcada dentro de esa acción de política pública. Ahora el replanteamiento de dichas políticas públicas están presionando a los agentes sociales, disuadiéndolos bajo la amenaza de la negociación el marco de un nuevo pacto políticoparlamentario, llamado a sustituir al ya "anticuado" y "desfasado" Pacto de Toledo 55 . En éste pacto político se opta por una dirección en la política de edad de jubilación, recogida en la Recomendación 100 de dicho Pacto, que apuesta, en primer lugar por impulsar la jubilación flexible, gradual y progresiva ( $\mathrm{La}$ edad de jubilación debe ser flexible y dotada de los caractereses de gradualidad y progresividad ); en segundo lugar, se inclina por mantener la edad ordinaria de jubilación a los 65 años; pero, al mismo, tiempo, en tercer lugar, por la conveniencia de que el acceso a la pensión de jubilación no debe impedir una presencia social activa del pensionista, por lo que que estima que resultaría aconsejable, en términos financieros y sociales, facilitarla prolongación voluntaria de la vida activa de quienes libremente lo deseen. Se trata, pues, de contener el proceso de expulsión del mercado de trabajo de edad madura. En esta lógica jurídica de prologanción de la permanencia en activo de los trabajadores de edad madura, se aboga proque se mantengan los sistemas de jubilación anticipada ligados a los contratos de relevo y de sustitución ya previstos en la legislación vigente ${ }^{56}$.

El marco adecuado para cambiar los mecanismos de las prejubilaciones podría ser la mesa de renovación del Pacto de Toledo. Es decir, en una perspectiva de conjunto sobre la reforma de las pensiones y del tratamiento de los objetivos de la política de Seguridad Social y del estudio de los equilibrios económico-financieros necesarios para el buen funcionamiento del sistema público. El nuevo contrato social debe reflejar el hecho de que los contextos diferentes requieren respuestas diferentes a las tradicionales. Los propios agentes sociales reconocen que el problema de las prejubilaciones debe abordarse de forma negociada con el Gobierno. Con todo, por la vía del consenso, se trata de alcanzar una solución equilibrada en la utilización de este mecanismo de tratamiento de los costes sociales de las reestructuraciones de empresas.

Como se puso de relieve existe una heterogeneidad de los instrumentos de regulación convencional del los planes de prejubilación, pero la figura estelar sin duda es el acuerdo de reorganización productiva. Ello no impide que existan a menudo convenios colectivos que prevean las condiciones generales en que han de realizarse los programas de prejubilación. Recuérdese que el derecho constitucional a la negocia-

55. Informe de la Ponencia para el análisis de los problemas estructurales del sistema de la Seguridad Social y de las principales reformas que deberán acometerse (BOCG, de 12 de abril de 1995, Serie E, núm.134). Públicado ahora en Informe de la Ponencia para el análisis de los problemas estructurales de la sistema de la Seguridad Social y de las principales reformas que deberän acometerse. Pacto de Toledo, Madrid, MTSS, 1996.

56. Sobre el tema véase MONEREO PÉREZJ.L.: El futuro de las pensiones. Sistema puiblicos y sistemas privados, en $R E D T$, núm. 88 y 89 (1998). 
ción colectiva (art.37.1 CE) admite una multiplicidad de productos jurídicos resultantes de la misma (convenios colectivos propiamente dichos y pactos o acuerdos colectivos de empresa). Tales acuerdos ex art.51.4 LET son manifestación de la negociación colectiva, pero anudados a una función participativa en la gestión de la empresa en dificultades. Es una negociación colectiva gestional que permite que los trabajadores incidan sobre los poderes empresariales de gobierno de la empresa.

b) Política de empleo y políticas de reorganización del sistema productivo.

En el marco de una economía global y altamente competitiva las empresas están adoptando medidas organizativas para adecuar su estructura, dimensiones y organización (formación de grupos, descentralización de actividades, etc.) a las exigencias imprimidas por el mantenimiento de los beneficios. Estas políticas invariablemente tiene por consecuencia normal la generación de excedentes de personal. En este sentido es frecuente que las grandes empresas configuren un "Plan de renovacion de Plantillan en el marco de un plan de viabilidad económico-financiera de carácter más general. Dentro de los expedientes de regulación de empleo (realizados por la vía jurídicamente normalizada del art.51 LET), las empresas en proceso de restructuración (interna o externa) suelen prever un doble régimen programado de tratamiento de las plantillas: por una parte, un sistema de reducción de plantilla; y por otra, una política de incorporación de nuevo personal idóneo para la realización de la empresa en reestructuración ${ }^{57}$.

La lógica subyacente en estos planes de regulación de empleo es la propia de la racionalización funcionalista instrumental para la acomodación del volumen de plantilla a las necesidades de la empresa, buscando una gestión consensuada de los problemas de gestión y del tratamiento de los excedentes de personal ${ }^{5 \%}$. De este modo el tratamiento de los excedentes se vincula a una política de fomento de la contratación de nuevos trabajadores, convirtiendo una medida típicamente defensiva (la extinción contractual por pregulación o jubilación anticipada) una medida típicamente ofensiva, al servicio del fomento del empleo de trabajadores más jóvenes (encadenamiento de las bajas producidas con compromisos de nueva contratación de personal desempleado). Junto a la incidencia de una modificación de la estructura empresarial, a cuyo fin frecuentemente se establece por vía convencional una obliga-

57. Es éste el caso, del Acuerdo colectivo de reorganización de la empresa Fuerzas Eléctricas de Cataluña, S.A.(FECSA), de 19 de enero de 1998. en el marco del período de consultas llevado a cabo para la aprobación del "Plan de Renovación de Plantilla". Para un análisis más amplio de estos Acuerdos en los diferentes sectores energéticos remitimos al Informe que realizamos, en colaboración con los profesores Moreno Vida y Gallego Morales, para la Comisión Consultiva Nacional. Aa.Vv. La negociación colectiva en el sector energético. MTAS.Madrid.2000. pägs.509 y sgs.

58. Véase MONEREO PEREZJ.L. Y FERNÁNDEZ AVILÉS.J.A.: El despido colectivo en el Derecho Español. Estudio de su régimen juridico. Pamplona, Aranzadi, 1997, passim. 
ción de negociar de buena fe çon vistas a alcanzar un acuerdo ${ }^{59}$, una de las cuestiones más relevantes es la del control de las situaciones postcontractuales previstas en la negociación colectiva, esto es, la relativas a las garantías y procedimientos de control colectivo ${ }^{60}$.

En todo caso, el protagonismo de la autonomia colectiva en un uso de gestión empresarial es evidente, tanto en el ámbito de la empresa como en un mercado interno de trabajo más amplio, el del grupo, que por esta vía alcanca un creciente protagonismo en el sistema de relaciones laborales, no obstante la permanente actitud abstencionista de la legislación en esta materia. Así, dentro del intento de gobierno consensuado del Grupo Endesa, tiene una importancia extraordinaria el acuerdo sobre los procesos de reorganización societaria y reorganización empresarial del Grupo Endesa por la dirección del Grupo Endesa, de 27 de abril de 1999 (BOE, núm.148, 22 junio 1999). Este acuerdo tiene la naturaleza jurídica de un convenio sobre materias concretas regulado en el título III de LET (art.1 del Acuerdo), no obstante los problemas que formalmente genera la constatación de una alegitimación cruzada no contemplada en el Estatuto de los Trabajadores ${ }^{61}$. Entre las garantías de empleo que se recoge destacamos en este momento las previsiones sobre la creación de procesos de recolocación, por suspensión temporal o por extinción definitiva de las actividades del centro de trabajo o de alguna de las unidades autónomas de producción, en cuyo caso el pesonal afectado tendrá derecho a reincorporarse en otro centro de trabajo de la empresa o de la empresa de origen, entendiendo como tales las resul-

59. Esta previsión convencional viene a ser reiterativa de la normativa legal, ya que la modificación de las condiciones de trabajo por via de modificación de la estructura de la empresa o de alteración sobrevenida de circunstancias exige un proceso negociador, no impeditivo de una decisión unilateral del empleador, ya que lo exigido (al igual que en el Acuerdo de reorganización empresarial) es la obligación de negociar, no el deber de alcanzar un acuerdo (art.41 LET), lo que supondría de ser así el reconocimiento del un virtual derecho de veto respecto de un eventual intento de modificación unilateral ex latere del empresario. Un ilustrativo ejemplo fue el del Acuerdo sobre el Plan de Empresa y Convenio Colectivo 1998-2001 de Hulleras del Norte, S.A. (Hunosa), de 27 de enero de 1998. Es de señalar que dicho Plan de reorganización se inserta en el marco de una planificación de la Compañia en su conjunto y unidad por unidad. En el Plan Hunosa de 1998 se establece un acuerdo que vincula las extinciones contractuales por prejubilación, con el también compromiso post-contractual de realizar nuevas contrataciones

60. En el plan Tabacalera de 1998 se acordó la creación de una Comisión de seguimiento, de composición paritaria, cuya parte social estará compuesta por representantes de las Centrales firmantes del acuerdo. Su función es velar por la aplicación, vigencia e interpretación de las medidas previstas en el ERE. Es una comision específica para la gobernabilidad de las situaciones postcontractuales (sus facultades son de carácter informativo, consultivo, examen conjunto, de mediación, arbitraje y conciliación). Analoga situación en el Plan Telefónica de España. En el caso del Plan de reestructuración del Grupo Enidensa de junio de 1998 (Acuerdo colectivo en periodo de consultas sobre plan de prejubilaciones eléctrico), el plan social de prejubilaciones se inserta en un plan general de reestructuración del Grupo Endesa

61. Para la problemática generada por este tipo de convenios vid STS 21.12.1999. En doctrina la crítica de MOLINA NAVARRETE, C: La regulación juridico-laboral...op.cit. 
tantes del proceso de separación de actividades de la Ley 54/1997. Se establen igualmente un régimen preferencial de circulación de trabajadores entre sociedades del grupo Endesa ${ }^{62}$.

Por lo que refiere al caso del Plan de reestructuración de Renfe de 16 abril de 1999 (plan con acuerdo en período de consultas), el plan social se inserta en un programa de viabilidad del futuro de la empresa. Se apuesta por un tratamiento no traumático de los excedentes de personal a través sobre todo de la técnica de la prejubilación. Pero se vincula a una política de fomento del empleo en la empresa: Se acuerda al efecto que el segundo año de vigencia del ERE (año 2000), se producirá la contratación de un trabajador por cada cuatro prejubilaciones que se suscriban, de personal que empiece a cumplir condiciones en dicho año 2000 , y siempre que como resultado de las mismas se mantenga el compromiso de plantilla media del contrato progra$\mathrm{ma}^{63}$. Como en anteriores experiencias comentadas, también aquí se fomenta la gestión consensuada de la política de gobierno de la empresa y se crea una Comisión de Seguimiento, formada por una representación de cada una de las partes firmantes del acuerdo, para la aplicación y desarrollo de los acuerdos en él contenidos. Se informará a esta Comisión de la marcha del Expediente de Regulación de Empleo. Así como se informará a esta Comisión de bajas incentivadas — de carácter residual respecto de los planes de prejubilación, auténtica estrella del acuerdo- que se denieguen.

Como se puede comprobar en todas estas experiencias recientes los procesos de reestructuración de las empresas se han afrontado en nuestro país, sobre todo en las grandes empresas y en los grupos de empresas, a través de mecanismos de gestión negociada, buscando la implicación de los trabajadores en las decisiones de reorganización de la empresa en crisis o en reestructuración. En este marco las empresas han elaborado planes negociados de viabilidad económica y ajuste de plantillas. En los planes sociales ha adquirido una especial importancia los programas de prejubilación sectoriales o de empresa. En tales las planes se regulan los elementos y condiciones de la medida de prejubilación y, señaladamente, los compromisos de sostenimiento económico por parte de la empresa. Esta práctica había tenido su impulso genético en los procesos de reconversión industrial, dentro del cuadro de medidas pretendidamente excepcionales y extraordinaria; para después normalizarse en las reestructuraciones llevadas a cabo sobre en el marco de los expedientes de regula-

62. Análogamente el I y II Acuerdo Marco del Grupo Repsol.En una perspectiva general se establece el compromiso de utilizar mecanismos no traumáticos en la política de bajas para conseguir el objetivo de adaptación de las plantillas en el conjunto del grupo. Al efecto se establece la posibilidad de bajas voluntarias por prejubilación, adquiriendo la empresa el compromiso de elaborar un plan de bajas para el personal (art.9). También se establece un sistema de movilidad interempresarial en el Grupo Repsol

63. El Plan negociado de reestructuración de Renfe se especifica en la "Circular de Prejubilaciones y Bajas Incentivadas 1999-2000 (Madrid, 16 abril 1999) 
ción de empleo ${ }^{64}$. Estos son ejemplos de la utilización sistemática de la técnica de la prejubilación en el marco de los planes sociales de reestructuración de la empresa. Nótese que precisamente que la regulación de los despidos por causas de funcionamiento de la empresa obliga a esa consideración de conjunto, ya que exige que las medidas extintivas propuestas contribuya, si las aducidas son económicas, a superar una situación económica negativa de la empresa o, sin son técnicas, organizativas o de producción, a garantizar la viabilidad futura de la empresa y el empleo en la misma a través de una más adecuada organización de los activos (art.51.1 LET y su reglamento, aprobado por $\mathrm{RD} .43 / 1996$, de 19 de enero) ${ }^{65}$.

c) Política de empleo y medidas de recolocación de los trabajadores excedentes.

Se puso de manifiesto la heterogeneidad de las cláusulas sobre empleo, e incluso aquéllas que afectan a contenidos típicamente postcontractuales, como los que atienden a las prejubilaciones, compromisos de recolocación del trabajador excedente, pactos de readmisión de trabajadores previamente despedidos cuando se produzca un oferta de empleo por parte de la empresa de originaria procedencia, etcétera. Estas últimas medidas, que centrarán ahora nuestra atención, no dejan de reflejar la progreisva pérdida de marginalidad de una política de empleo realizada desde instancias privadas. Si hasta el momento este tipo de cláusulas sólo ha permitido una ordenación cuantitativamente reducida de la oferta de empleo, cada vez son más

64. Así lo ponen de manifiesto los programas de prejubilación adoptadas en los planes del Grupo CruzCampo (1996), Agroman (1995), Iberia (1994), HOESCH (1994), Acuerdo sobre Plan de Competitividad de CESA (1993), Gnipo empresarial ABB (1993), SEAT (1993), REFE (1992), Hunosa (1992), Plan industrial de Futuro 1992-94, Firestone (1992), Alcatel, Standar Eléctrica (1991), Minas de Almadén (1990); Empresa Nacional Santa Bárbara de Industrias Militares (1994), Empresa Nacional ADARO (1994), S.A.Cros (1988), Renault (1988), Empresa Nacional de Autocamiones (1986).Sobre estas "prejubilaciones programadas" realizadas en los últimos años, véase, por todos, LOPEZ CUMBRE,L.: La prejubilación, cit., págs.188 y sigs. Esta autora constata que existe una amplia variedad de posibilidades de ordenación de las prejubilaciones, tanto por lo que se refiere al modo de financiación, como al tipo de obligaciones contraídas por el propio trabajador prejubilado. En este sentido existen planes empresariales en los cuales se obliga al trabajador expresamente a no establecer ningún tipo de relación profesional (Caja de Ahorros y Monte de Piedad de Castellón, 39 octubre 1991); o se condiciona el compromiso contraído por la empresa al abandono definitivo de esa. empresa, exigiendo al trabajador que no vuelva a trabajar ni en la empresa en la que se prejubila ni en empresas del grupo actuales o futuras.Por otra parte, los programas de prejubilación pueden reclamar prestaciones públicas o exclusivamente privadas; o mixtas, que es lo normal. Se puede decir que, en términos generales, la doctrina jurisprudencial admite, salvo pacto en contrario, la obligación de mantener los complementos aunque no se concedan las prestaciones base deduciendo de la cantidad global acordada el importe correspondiente a la pensión pública no concedida. cfr.STS 4 marzo 1997, AV2243 (Ibid.,pág.187).

65. Véase MONEREO PÉREZJ.L. Y FERNÁNDEZ AVILÉS J.A.: EEmpresa y despido. La extinciōn del contrato de trabajo por causas de funcionamiento de la empresa, en AA.VV., MONEREO PÉREZ,J.L.(Coord.): La reforma del mercado de trabajo y el fomento de la contratación indefinida, Granada, Comares, 1998. 
abundantes estas cláusulas convencionales como expresión del creciente protagonismo de las políticas de gestión consensuada de los mercados internos de trabajo.

Resulta obvio que, en general, la posibilidad de encontrar un nuevo empleo por parte del trabajador despedido dependen en gran medida de las oportunidad de empleo creadas por una satisfactoría marcha de la economía y está, por consiguiente, en función de las variables del ciclo económico y la variable autónoma, pero no siempre independiente, de las políticas públicas en materia de ordenación de la economía productiva. De cualquier modo, la negociación colectiva en el ámbito de la gran empresa ha regulado mecanismos de recolocación de los trabajadores originariamente excedentes. La idea-fuerza es facilitar la permanencia en el mercado laboral de los trabajadores inicialmente excedentes, pero tras este objetivo transparente late también el intento de amortiguar los conflictos sociales generados por la expulsión de los trabajadores excedentes. No obstante la experiencia jurídica conoce dos tipos de procesos de recolocación según que se trata de reestructuraciones ordinarias o extraordinarias de la empresa o del sector. La que sigue es la regulación de la dualidad de supuestos especiales de recolocación de los trabajadores excedentes:

A) Primer supuesto: reestructuración ordinaria de la empresa o grupo de empresas.

Respecto a la recolocación -que no siempre implica una auténtica recontrataciónde los trabajadores en el seno de los grupos de empresas existe una marco normativo estatal de alentamiento o promocional (art.6.1,c) del RD. 43/1996, de 19 de enero). En este ámbito socio-económico, el plan social de acompañamiento puede (nótese el carácter facultativo de la inclusión de este tipo de cláusula dentro del plan de reorganización) prever medidas de recolocación internas al grupo, como ya antes en los proceso de reconversión industrial (y en algunos planes sociales de grupo de empre- sas) se había previsto incluso en el cuadro de la recolocación del sector de actividad económica. Lo que por cierto sigue siendo posible con el marco actualmente vigente (art.51 LET, y normativa de desarrollo, y Directiva comunitaria sobre despidos colectivos). El grupo de empresas es contemplado como un mercado de trabajo interno. En relación con esa norma estatal de carácter "débilmente" promocional, existen algunos exponentes recientes en la normación convencional del recurso a esta medida de recolocación en el ámbito del grupo, en aras de un pretendido interés conjunto o común al "mantenimiento" de los actuales niveles de empleo ${ }^{66}$. Estos pactos de

66. Así el Convenio colectivo interprovincial de -Amper comercial de servicios electrónicos, S.A (AmperCosesa), Año 1997 (BOE, 7 octubre 1997, núm.240), en cuyo Cap.IX, art.35. En el Grupo Repsol, se establece que los excedentes de plantillas de las empresas del grupo están sujetos al procedimiento de movilidad interna dentro del grupo de empresas (art.4.4. del I Acuerdo Marco del Grupo Repsol). Este circuito de movilidad impeditivo de la expulsión del trabajador se inserta en el marco de la racionalidad del grupo empresarial, conjugando los intereses del grupo y el interés del trabajador a obtener un empleo en su seno. 
recolocación y/o readmisión de trabajadores - cuando hayan sido previamente despedidos- han proliferado en la negociación colectiva, encontrando su previsión no sólo en los acuerdos específicos de reorganización productiva, sino también su regulación más general en los convenios colectivos que cada vez más frecuentemente conocen de la existencia de tales cláusulas convencionales ${ }^{67}$.

Este tipo de medidas de política activa de empleo (que dan lugar a relaciones post-contractuales), aunque en el ámbito del grupo de empresas contemplado aquí como mercado interno de trabajo, se sitúan dentro de un modelo de autoregulación social vinculado con la dinámica de funcionamiento de la empresa. Este modelo integrador (en el plano de la gestión participada y en el de la articulación de las medidas predispuestas para afrontar la continua adaptación de las empresas a los cambios del entorno) es plenamente admisible, y coherente, con la lógica que informa a la Directiva sobre despidos colectivos y al propio art.51 LET, y su desarrollo reglamentario (RD. 43/1996, 19 enero $^{68}$ ).

Con todo, se produce una normalización de una figura que nació íntimamente vinculada a los proceso de reconversión industrial, como supuestos de reestructuración extraordinaria de las empresas. Estas medidas de política de empleo activa hace posible, y más fácilmente aceptable, la adopción de mecanismos de flexibilidad en los mercados de trabajo. Pero también puede también puede ser una medida ajustada con al principio de equidad respecto de los trabajadores desempleados o incluso procedentes de industriales en declive. Lo que nos lleva de inmediato a la consideración de las reestructuraciones sectoriales o de tipo extraordinario.

B) Segundo supuesto: reestructuración extraordinaria de la empresa. Planes de reconversión industrial y planes de reestructuración en el marco de políticas de reorganización industrial.

El marco general del tratamiento de los excedentes de plantilla en la negociación colectiva integrada con el intervencionismo público en la reorganización industrial, son sin duda las políticas de concertación social, como negociación sociopolítica

67. Asî, el convenio de La Coruña de Comercio de Alimentación, Mayor y Detall, garantiza para todos los trabajadores despidos por reestructuración o causas relacionadas con el funcionamiento de la empresa (arts. 51 y 52 ,c) LET), la obligación empresarial de readmitir a las personas afectadas en los supuestos en que la empresa realiza después un aumento del volumen de la plantilla ocupada en la misma. También en el convenio de La Coruña de Comercio de Alimentación, de Frutas y Verduras, se indica que en relación con el despido por causa de reestructuración de la empresa, los trabajadores afectados son titulares de un derecho a ser readmitidos preferentemente en el caso de que la empresa efectúa con posterioridad un aumento de la plantilla.Véase SALA FRANCO, T., y otros.: Informe sobre..., págs.232 y sigs.

68. La medida de recolocación se había ya puesto en práctica incluso antes de la previsión específica del desarrollo reglamentario. Así en los planes de vialidad, de INSEL, Empresa Nacional Electrónica y Sistemas (1993), Adara, Empresa Nacional (1994), Agroman, Empresa constructura (1995). 
sobre las situaciones de crisis y reestructuración del sistema productivo. Dentro de ese marco la negociación colectiva de reestructuración ha constituido una pieza esencial para la puesta en práctica de los objetivos previamente trazados por los pactos de concertación social, y especialmente los pactos tripartitos de reestructuración de sectores de actividad económica o de grupos de empresas en dificultad (también sometido a planes de reestructuración). Esta conjunción de instrumentos ha permitido un enriquecimiento de los planes socio-políticos de empleo: integrando medidas "privadas" y medidas "públicas", combinadas y articuladas para el tratamiento de las empresas en crisis o en proceso de reestructuración productiva.

Precisamente en el cuadro de medidas de tratamiento de los excedentes de plantillas, se han insertado las medidas activas de empleo: formación profesional adaptativa a los transformaciones tecnológicas y organizativas del sector y recolocación de los trabajadores excedentes en otras empresas del sector o dentro del grupo de empresas en reconversión —art.18 de la Ley 27/1984, de 26 de julio, sobre Reconversión y Reindustrialización (LRI) - o el Fondo de Promoción de Empleo $(\mathrm{FPE})^{69}$. A este FPE, de creación facultativa por cada plan de reconversión se incorporan y permanecen los trabajadores excedentes. Su finalidad es compleja: en el aspecto "reparador" reside en la mejora de la intensidad de la protección por desempleo, complementando las prestaciones básicas y complementarias y ampliando su duración; y en el aspecto de la política "activa", asumían la función de colaborar en la recolocación en nuevos empleos de los trabajadores afectados por la reconversión, mediante la incentivación económica a la creación de empleos de carácter estable y la readaptación profesional de los trabajadores excedentes (art.22.1 LRI) ${ }^{70}$.

El proceso gradual -pero lento- de agotamiento de las políticas de reconversión, a medida que se iban llevando a cabo las reestructuraciones previstas y las nuevas incorporaciones imprimidas por las exigencias del mercado y de las prescripciones de la Comunidad Europea ${ }^{71}$, produce una suerte de desplazamiento vertical de los mecanismos de reestructuración, en primer lugar, hacia el modelo de regulación general o común previsto en el sistema del Estatuto de los Trabajadores y en la legislación general

69. Institución, ésta, configurada ccomo asociaciones sin ánimo de lucro, con personalidad jurídica propia, y tendrán el carácter de entidades colaboradoras del Instituto Nacional de Empleo. actuando bajo la inspección del mismon. cfr.art.22.2 LRI.

70. En la práctica era una fictio iuris hablar de que los trabajadores mantenía su originario contrato de trabajo en suspenso, dando por hecho los que casi nunca se produzco: que los trabajadores alguna vez. superada la situación de crisis, se incorporaría a su empresa de pertenencia. En realidad, la experiencia jurídica demostraria, todo lo contrario, que los FPE actuaban como un mecanismo puente entre la situación de desempleo y la prejubilación o jubilación definitiva del trabajador; o, en el menor de los casos. su recolocación en otra empresa del sector o del grupo de empresas

71. Sobre la evolución posterior de los procesos de reconversión industrial, véase MONEREO PÉREZJ.L.: -Las políticas laborales de reconversión realizadas en Españan, en Relasur/OIT, núm.5 (1995), págs.9 a 61. 
de Seguridad Social, y en segundo lugar, hacia la realización de políticas "menos excepcionales "de promoción industrial. En ambos casos configurando planes sociales integrados en un más amplio plan de viabilidad de la empresa, del sector o, en su caso, de promoción del desarrollo en regiones más deprimidas o con sectores industriales en declive que deben ser asistidos o desaparecer para ser sustituidos por sectores con futuro. Hito importante en esa evolución en la aprobación de la Ley de Industria, 21/ 1992 , de 16 de julio, y varias normas posteriores en desarrollo de la misma ${ }^{72}$.

\section{3. nuevas" modalidades para garantizar convencionalmente el equilibrio cuantitati-} vo entre la oferta y la demanda de empleo en los mercados internos

Pero junto a estas fórmulas tradicionales, o mejor, clásicas de intervención de la autonomía colectiva en la gestión de los niveles de empleo de una empresa, grupo o sector de actividad, proliferan en los acuerdos y convenios colectivos otro tipo de cláusulas que inciden de diverso modo en los objetivos de creación de empleo, mejora de su calidad (=estabilización=) y redistribución de los ya existentes (= cláusulas de solidaridad $=$ ), presentes en la moderna política de empleo. Si los convenios de empresa se revelan como los más favorables a introducir cláusulas de creación de empleo neto, por la evidenciada proximidad entre la fuente reguladora y la situación concreta del ámbito socioeconómico regulado, los convenios de sector parecen evidenciar una mayor proclividad a introducir cláusulas de garantía de empleo, esto es, básicamente orientadas bien a mantener los actuales niveles de empleo (ej. compromisos orientados a garantizar el mantenimiento de un determinado porcentaje de plantilla; renuncia al ejercicio durante su vigencia de las facultades extintivas por cuasas económicas..), bien a promover su mayor estabilidad (ej. pactos sobre conversión de contratos temporales en fijos; claúsulas orientadas a "penalizar" o desincentivar el recurso al empleo temporal; cláusulas de recolocación y/o readmisión de trabajadores afectados por extinciones... $)^{73}$.

72. Sobre la incidencia iuslaboral de esta ley en el marco de los procesos de reestructuración de plantillas, véase MONEREO PÉREZJ.L.: Los despidos colectivos en el ordenamiento interno y comunitario, Madrid, Civitas, 1994, poniendo de relieve la necesidad de observar las exigencias de procedimentación participada previstas en la Directiva sobre despidos colectivos. Esta Ley establece medidas laborales y de protección sociales especiales para la consecución del fin por ella propuesto (la promoción industrial), pero observando escrupulósamente la tramitación laboral común u ordinaria. Entre ellas se encuentran la facilitación de la liberación de los excedentes del personal de edad madura en el marco de la elaboración por la empresa de un programa de promoción industrial que comprenda un conjunto de medidas sociales de acompañamiento, como las medidas de prejubilación (art.2).

73. Para la estadística del número de convenios y porcentaje de trabajadores por tipología de las cláusulas de empleo, desde 1994 hasta 1999, vid. Oservatorio de Relaciones Industriales, del CES, n.32, agostoseptiembre 2000. Un ejemplo reciente de estas cláusulas de remisión a las facultades legalmente previstas, tanto en el plano estatal como autonómico, para acogerse a programas de fomento de empleo en el art. 6 CC Empresas Cargill España, S.A. y AOP Iberia, S.L, Planta Envasadora de Aceites - BOE 27.6.2001-. 
No obstante, tampoco en este segundo grupo de cláusulas de empleo los resultados pueden entenderse realmente satisfactorios, como evidencia la propia crítica evidenciada por los interlocutores sociales, que consideran una auténtica prioridad para la negociación colectiva de los próximos años hacer efectivos los compromisos adquiridos en el AIEE. En este sentido, junto a la recomendación del establecimiento de compromisos fehacientes, traducibles en derechos subjetivos, que permitan a los trabajadores reclamar la apertura de un proceso de cobertura de vacantes o la conversión de contratos temporales (=cláusulas ocupacionaes de cuantificación directa=), proliferan las denominadas cláusulas desincentivadoras —cuando no lisa y llanamente prohibitivas- de la contratación temporal, así como de cualquier modalidad o forma de contratación "precaria", incluidas las formas de exteriorización de la organización del trabajo. A tal fin, se requiere sea la causalización rigurosa de la contratación temporal, se fijan porcentajes de utilización que actúan como máximos convencionales o se establecen indemnizaciones (=tutela monetaria=) que incrementan el coste de estos contratos $^{74}$.

Pero sin duda, entre estas claúsulas de garantía de empleo estable un papel particularmente destacado, pero extraordinariamente polémico, es el cumplido por las cláusulas restrictivas $\longrightarrow$ incluso prohibitivas - de la contratación temporal indirecta, esto es, del recurso a las ETTs. Aunque la gama es muy variada, destacan por su especial conflictividad jurídica, evidenciada no sólo por los términos en que se define sino traducida en pronunciamientos de los Tribunales de Justicia, tanto las denominadas "cláusulas probibitivas" de la contratación indirecta cuanto las "cláusulas de equiparación salarial.. La cláusulas de tutela frente al uso - y abuso- de las formas de utilización externa o de gestión indirecta de las relaciones de trabajo hacen, de esta manera, acto de presencia en la negociación colectiva ${ }^{75}$, procurando restringir unas vías de acceso permitidas no sólo por la flexible regulación legal sino también por la tolerancia mostrada por los Tribunales de Justicia y la "fantasía creativa" de la práctica empresarial,

74. vid. MOLINA NAVARRETE, C-MOlina HERMOSILla, O- CAÑADA Villa, I. Derecho $y$ Empleo...op.cit.pags.64 y sgs. Aunque el CES lo ha visto de otra manera, parece claro que aquellas cláusulas orientadas a prolongar el periodo de duración de las modalidades contractuales previstas en el arr.15, sin establecer una garantia precisa de conversión en empleo indefinido, tuvieron más el efecto precarizador que estabilizador. Un ejemplo de cláusula de empleo que garantiza el mantenimiento de un porcentaje de plantilla estable es el art.10 CC Interprovincial de las empresas de minoristas de Droguerias, herboristerias, ortopedias y perfumerias - BOE 28.11.2000-; art.10 CC Estatal para las empresas organizadoras de Bingo - BOE 30.1.2001-

75. Como se ha observado, un balance global sobre la inserción de cláusulas de empleo en la negociación colectiva más reciente, pone de manifiesto la aparición de nuevas regulaciones convencionales sobre esta temática, asumiendo, en este sentido, los acuerdos sucritos a nivel interconfederal por los sindicatos y las organizaciones empresariales, asi como una presencia creciente de este tipo de compromisos en algunos convenios colectivos, debido a que una situación económica más favorable habría facilitado su inclusión. CES, Observatorio de Relaciones Industriales, n.232, cit. 
así como por la propia laxitud con que se ha desarrollado una determinada práctica convencional, en especial la proliferación de convenios colectivos de empresa en el ámbito de las ETTs. Por vía convencional se contrarresta, pues, esta práctica convencional empresarial ad boc, flexibilizadora de la gestión de personal temporal, al tiempo que anticipa y/o acompaña la regulación posteriomente seguida en el ámbito sectorial ( ej. II CC ETTs/1997 —se ha aprobado ya el III CCETTs/2000—) ${ }^{76}$.

El primer tipo de cláusulas referidas supone la renuncia vía obligación colectivamente impuesta al ejercicio de un a facultad de contratación legalmente prevista, con el consiguiente contraste de la libertad constitucional de empresa ex art.38 C.E. El segundo tipo representan la introducción de una obligación salarial suplementaria o adicional directamente a cargo de las empresas usuarias y en favor de los trabajadores en misión que, fundamentada en el principio de igualdad de trato y en la libertad de negociación, puede suponer una importante lesión de los intereses económico-competitivos de las ETTs, con la consiguientè vulneración del principio de libre competencia ex art.38 C.E. La división radićal de la doctrina judicial en dos posiciones opuestas, una favorable a la validez y eficacia de dichas cláusulas, en particular las de equiparación salarial, y otra contraria a su validez por su eventual lesividad a los intereses de terceros (=ETTs $=$ ), abre importantes interrogantes para los que no existe hasta el momento una respuesta suficientemente convicente ni en la doctrina ni en la jurisprudencia, por lo que a falta de una doctrina unificadora razonablemente segura cabe un amplio margen para el trabajo del jurista científico.

En el ámbito del sector público del empleo merece especial consideración los acuerdos entre la Administración Pública, fundamentalmente autonómica, pero también en el ámbito de Entidades Locales y de Organismos Autónomos -Administración Institucional, en favor del empleo en estos ámbitos, en particular nos referiremos aquía a los Acuerdos de Estabilización del personal empleado de forma temporal, cuyo crecimiento en estos últimos años ha disparado todas las alarmas, y los Acuerdos de reducción de la jornada a las míticas 35 horas, con objeto de crear más empleo a través de un reparto solidario del existente. Sin duda estos últimos son los más novedosos - dejamos al margen el incremento, tanto en el ámbito privado como en el público, de los acuerdos para la reducción del trabajo extraordinario y de las situaciones de pluriempleo- y revelan una opción de política de empleo diferente a la adoptada en el ámbito del empleo privado, tanto por el Gobierno como por los interlocutores sociales, especialmente como consecuencia de la oposición empresa-

76. vid. las diversas cláusulas condicionadoras en el art.12 CC empresas minoristas de droguerias... op.cit. - BOE 28.11.2000 - Para las cláusulas de equiparación salarial en sentido pleno vid. Acuerdo Estatal para el Sector de Fabricantes de Yesos, Escayolas, Cales y sus Prefabricados, así como el Acta Adicional en materia retributiva - BOE 12.8.1999-. En el mismo sentido, aunque con redacción diferente; D.A.90 CC Centro de Educación Universitaria e Investigación — BOE 31.3.2000—. 
rial a firmar acuerdos de reducción de jornada directamente orientada a generar nuevos empleos. La reducción de jornada no se plantea como un fin en sí mismos, producto de una simple mejora negociada de las condiciones de trabajo del personal, sino como una medida que tiene por objeto la creación de empleo.

A tal fin, se establecen compromisos específicos en porcentajes y número de efectivos, si bien de forma progresiva y definiendo áreas prioritarias, que suelen identificarse con el ámbito de los nuevos yacimientos de empleo —ej. Acuerdo 9.3.1999 de la Consejería de Gobernación y Justicia por el que se aprueba el Acuerdo entre la Administración General de la Junta de Andalucia y las Organizaciones Sindicales más representativas (BOJA 39/1999, 3.4)-. El fomento de esta reducción del tiempo de trabajo en empresas públicas y organismos autónomos, con objeto de aumentar los niveles de empleo, aparece también en el Acuerdo sobre incentivos a la contratación por reordenación y reducción del tiempo de trabajo firmado, el 26.2.1999, entre el Gobierno de Navarra y las 2 Centrales Sindicales más representativas de la Comunidad Foral de Navarra 77 . En los diferentes supuestos la via adecuada para materializar estas medidas es la de la negociación colectiva, previendo algunas de estas normas autonómicas su proyección también al sector privado, mediante acuerdos de empresa o sectoriales en los que se concrete esa reordenación del tiempo de trabajo, si bien siempre sin perjuicio de la competitividad.

La negociación colectiva aparece también como instrumento de optimización de los nuevos yacimientos de empleo. En este sentido, se ha solicitado una "especial sensibilidad " de este mecanismos regulador para el impulso de los nuevos yacimientos de empleo, al objeto de aprovechar al máximo rendimiento todos y cada uno de los aspextos de la regulación que inciden mas incisivamente en el volume de empleo en la empresa y en el sector ${ }^{78}$. Entre estas materias destaca la contratación, en particular el recurso a determinadas modalidades tales como el trabajo a tiempo parcial, el contrato formativo o el contrato de insercion pueden tener influencia o efectos determinantes sobre el volumen y calidad de empleo.

$\checkmark$

77. La interesante Ley Foral 9/1999 - BON 43/1999, 9.4-, sobre una Carta de Derechos Sociales, ya recoge entre los elementos necesarios para hacer efectivo el derecho constitucional al empleo una política de reparto del tiempo de trabajo, de modo que se conduzca, negociadamente. una reordenación y reducción del trabajo hasta llegar a las 35 horas. En una dirección análoga el Decreto 47/1999, 18.2, por el que se regulan los incentivos a la contratación laboral por reordenación del tiempo de trabajo que implique creación de empleo neto en Galicia -DOG 47/1999, 2.3, c.e. 47/1999, 9.3-, y que tiene su antecedente en el Acuerdo de medidas para la reordenación del tiempo de trabajo y la creación de empleo en Galicia, entre la Xunta y CCOO, UGT, CEG, suscrito el 13.7.1998 y vigencia hasta el 2001.

78. vid.CANO SOLER, D..Nuevas oportunidades de empleo en España". RIEE.n.3.1999; Aa.Vv. (Dir. M.Rodriguez-Piñero).Nuevas Actividades y sectores emergentes: el papel de la negociación colectiva. MTAS. 2001. pág.415. 